\title{
Transcriptomic analysis of patients with tetralogy of Fallot reveals the effect of chronic hypoxia on myocardial gene expression
}

\author{
Mohamed T. Ghorbel, PhD, Myriam Cherif, PhD, Emma Jenkins, PhD, Amir Mokhtari, MRCS, \\ Damien Kenny, MRCPCH, Gianni D. Angelini, FRCS, and Massimo Caputo, MD
}

Objectives: In cyanotic patients undergoing repair of heart defects, chronic hypoxia is thought to lead to greater susceptibility to ischemia and reoxygenation injury. We sought to find an explanation to such a hypothesis by investigating the cardiac gene expression in patients with tetralogy of Fallot undergoing cardiac surgery.

Methods: The myocardial gene profile was investigated in right ventricular biopsy specimens obtained from 20 patients with a diagnosis of cyanotic $(n=11)$ or acyanotic $(n=9)$ tetralogy of Fallot undergoing surgical repair. Oligonucleotide microarray analyses were performed on the samples, and the array results were validated with Western blotting and enzyme-linked immunosorbent assay.

Results: Data revealed 795 differentially expressed genes in cyanotic versus acyanotic hearts, with 198 upregulated and 597 downregulated. Growth/morphogenesis, remodeling, and apoptosis emerged as dominant functional themes for the upregulated genes and included the apoptotic gene TRAIL (tumor necrosis factor-related apoptosis-inducing ligand), the remodeling factor $O P N$ (osteopontin), and the mitochondrial function gene COXI1 (cytochrome-c oxidase 11). In contrast, transcription, mitogen-activated protein kinase signaling, and contractile machinery were the dominant functional classes for the downregulated genes, which included the calcium-handling gene $N C X 1$ (sodium-calcium exchanger). Protein levels of COX11, NCX1, OPN, and LYZ (lysozyme) in the myocardium followed the same pattern obtained by means of transcriptomics. The TRAIL level did not change in myocardium but increased in circulating blood of cyanotic patients, suggesting the myocardium as a possible source. Additionally, our data showed increased protein expression of apoptosis markers in cyanotic myocardium.

Conclusions: Chronic hypoxia in cyanotic children with tetralogy of Fallot induced the expression of genes associated with apoptosis and remodeling and reduced the expression of genes associated with myocardium contractility and function. (J Thorac Cardiovasc Surg 2010;140:337-45)

Supplemental material is available online.

Cyanotic pediatric patients undergoing cardiac surgery are exposed to a chronic hypoxic state that can reduce their antioxidant reserve capacity, leading to a greater susceptibility to the oxidative stress of ischemia and reperfusion at the time of surgical correction..$^{1-3}$ Our group has shown that cyanotic children have worse myocardial reperfusion injury and clinical outcomes compared with acyanotic children after

\footnotetext{
From the Bristol Heart Institute, University of Bristol, Bristol Royal Infirmary, Bristol, United Kingdom.

This work was funded by the British Heart Foundation, the Garfield Weston Trust and the Bristol NIHR BRU in Cardiovascular Medicine. M. T. Ghorbel was supported by an Intermediate Research Fellowship from the British Heart Foundation. Disclosures: None.

Received for publication Aug 1, 2009; revisions received Nov 19, 2009; accepted for publication Dec 19, 2009; available ahead of print April 23, 2010.

Address for reprints: Massimo Caputo, MD, Bristol Heart Institute, Bristol Royal Infirmary, Bristol BS2 8HW, United Kingdom (E-mail: M.Caputo@bristol.ac.uk). $0022-5223 / \$ 36.00$

Copyright (c) 2010 by The American Association for Thoracic Surgery doi:10.1016/j.jtcvs.2009.12.055
}

similar periods of ischemic cardioplegic arrest. ${ }^{4}$ We have also shown that reintroduction of high oxygen levels to cyanotic patients undergoing cardiopulmonary bypass $(\mathrm{CPB})$ leads to myocardial damage before ischemic cardioplegic arrest. ${ }^{5}$ Our results suggest that the injury seen after cardioplegic arrest might in part be due to $\mathrm{CPB}$-induced reoxygenation injury, and this has also been demonstrated in previous studies. ${ }^{6}$

Several recent studies have used microarray technology to examine the global myocardial stress response during cardiac surgery, focusing on the human congenitally malformed hearts. ${ }^{7-10}$ Kaynak and colleagues ${ }^{7}$ examined gene expression profiles in patients with tetralogy of Fallot (TOF), ventricular septal defect, and right ventricular hypertrophy (RVH) compared with profiles seen in those with normal hearts. Another investigation examined gene expression changes in patients with cyanotic TOF in comparison with those seen in patients with normal hearts and showed that the upregulation of genes encoding vascular endothelial growth factor (VEGF) and extracellular matrix proteins are the key events contributing to RVH and stunted angiogenesis in patients with TOF. ${ }^{10}$ Konstantinov and associates ${ }^{8}$ examined the gene expression profiles in children undergoing 


$$
\begin{aligned}
& \text { Abbreviations and Acronyms } \\
& \begin{aligned}
\text { BAX } & =\text { Bcl-2-associated X protein } \\
\text { CPB } & =\text { cardiopulmonary bypass } \\
\text { ELISA } & =\text { enzyme-linked immunosorbent assay } \\
\text { ERK } & =\text { extracellular signal-regulated kinase } \\
\text { FDR } & =\text { false discovery rate } \\
\text { MAPK } & =\text { mitogen-activated protein kinase } \\
\text { RVH } & =\text { right ventricular hypertrophy } \\
\text { TOF } & =\text { tetralogy of Fallot } \\
\text { VEGF } & =\text { vascular endothelial growth factor }
\end{aligned}
\end{aligned}
$$

cardiac surgery for right heart obstructive lesions, including TOF, and showed that neonatal myocardium has a unique pattern of gene expression dominated by genes with cardioprotective, antihypertrophic, and antiproliferative properties, reflecting a stress-induced protective program.

However, to our knowledge, no previous genome-wide investigation has been made to determine the global gene expression profiles associated with chronic hypoxia in patients with TOF. The aim of this study was therefore to investigate the global ventricular myocardial gene expression profiles of cyanotic and acyanotic patients with a diagnosis of TOF undergoing corrective cardiac surgery.

\section{MATERIALS AND METHODS}

Twenty patients with a diagnosis of cyanotic $(n=11)$ or acyanotic $(n=9)$ TOF undergoing surgical repair at the Bristol Royal Hospital for Children were studied. All patients were in stable condition without preoperative respiratory or inotropic support. Preoperative characteristics in the 2 groups are summarized in Table 1. Patients with cyanotic TOF presented with several episodes of spells and repeated saturation measurements of less than $90 \%$ (mean, $79.6 \% \pm 7.5 \%$ ), whereas patients with acyanotic TOF did not have a history of cyanotic spells and presented with saturations of greater than $90 \%$ (mean, $94.2 \% \pm 3.5 \%$ ). Preoperative echocardiographic data showed significant gradient across the right ventricular outflow tract in both groups. The study was approved by the hospital research ethics committee, and parental informed consent was gained for all patients. Intraoperative anesthetic and operative techniques were standardized, as previously reported. ${ }^{4}$ After the operation, all patients were admitted to the pediatric intensive care unit and were managed according to unit protocols. ${ }^{4,5}$

Postoperative inotropic support was considered to be either minimal (dopamine $\leq 5 \mathrm{~kg}^{-1} \cdot \min ^{-1}$ for $\leq 24$ hours) or significant (dopamine $>5 \mu \mathrm{g} \cdot$ $\mathrm{kg}^{-1} \cdot \min ^{-1}$ with or without other inotropic agents, such as adrenaline, noradrenaline, or milrinone). Decisions regarding inotropic support and ventilation were based on hemodynamic status (eg, low mixed venous saturation and high lactic acidosis) and clinical judgment. ${ }^{4,5}$

\section{Cardiac Muscle Biopsy Specimens}

\begin{tabular}{|c|c|c|c|}
\hline & $\begin{array}{c}\text { Cyanotic } \\
\text { patients } \\
(n=11)\end{array}$ & $\begin{array}{c}\text { Acyanotic } \\
\text { patients } \\
(\mathbf{n}=\mathbf{9})\end{array}$ & $\begin{array}{c}P \\
\text { value }\end{array}$ \\
\hline Age (mo) & $10.6 \pm 5.5$ & $9.5 \pm 2.3$ & .1 \\
\hline Weight $(\mathrm{kg})$ & $8.04 \pm 1.7$ & $8.01 \pm 1.0$ & .7 \\
\hline RVOT velocity (m/s) & $4.6 \pm 0.4$ & $4.4 \pm 0.7$ & .2 \\
\hline $\mathrm{RV}$ wall indexed $\left(\mathrm{mm} / \mathrm{m}^{2}\right)$ & $16.6 \pm 3.0$ & $17.1 \pm 1.9$ & .1 \\
\hline VSD size $(\mathrm{mm})$ & $9.9 \pm 1.3$ & $9.8 \pm 1.6$ & .1 \\
\hline Use of preoperative $\beta$-blockers & 4 & 1 & .05 \\
\hline Preoperative $\mathrm{O}_{2}$ saturation (\%) & $79.6 \pm 7.5$ & $94.2 \pm 3.5$ & .01 \\
\hline Crossclamp time (min) & $78.0 \pm 15.6$ & $73.0 \pm 20.7$ & .1 \\
\hline CPB time (min) & $132.0 \pm 29.0$ & $90.2 \pm 17.7$ & .05 \\
\hline In-hospital mortality & 0 & 0 & \\
\hline $\begin{array}{l}\text { Inotropic support } \\
\quad(\text { minimal/significant })\end{array}$ & $1 / 10$ & $7 / 2$ & .01 \\
\hline Inotropic duration (h) & $54(42-136)$ & $22(12-29)$ & .03 \\
\hline Total $\mu \mathrm{g}$ dopamine $/ \mathrm{kg}\left(\times 10^{3}\right)$ & $16.3(12.2-36.3)$ & $5.2(1.9-7.3)$ & .01 \\
\hline Postoperative ventilation time (h) & $42(24-77)$ & $18(5-33)$ & .01 \\
\hline Postoperative ICU stay (h) & $87(49-122)$ & $40(26-48)$ & .001 \\
\hline Postoperative hospital stay (d) & $11(9-12)$ & $7(5-9)$ & .05 \\
\hline
\end{tabular}

Ventricular biopsy specimens (10 mg net weight) were collected from the apex of the right ventricle by using a "Trucut" needle ${ }^{4}$ immediately after institution of CPB. Each specimen was immediately put in RNA Later solution (Qiagen, Crawley, United Kingdom) and kept overnight at $4{ }^{\circ} \mathrm{C}$. The next day, RNA Later solution was removed, and biopsy specimens were kept at $-80^{\circ} \mathrm{C}$ until RNA extraction.

The concentration of total RNA samples was assessed by means of spectrophotometry (Nanodrop, Wilmington, Del) and was further analyzed for
TABLE 1. Baseline patients' characteristics and clinical outcomes

Data are presented as means \pm standard deviations or medians (interquartile ranges). $R V O T$, Right ventricular outflow tract; $R V$, right ventricular; $V S D$, Ventricular septal defect; $I C U$, intensive care unit.

integrity with a Bioanalyzer 2100 with RNA 6000 Nano Assay (Agilent Technologies, Stockport, United Kingdom).

\section{Gene Microarrays: Data Analysis}

Ventricular total RNAs $(1 \mu \mathrm{g})$ from individual patients were processed as previously described. ${ }^{11}$ Raw data (CEL files) were uploaded into ArrayStar software version 2.1 (DNASTAR, Inc, Madison, Wis) for normalization and statistical analysis. The robust multichip analysis algorithm was used for background correction, quantile normalization, and median polish summarization. The statistical analysis was carried out with ArrayStar software. A Student's $t$ test and Benjamini and Hochberg multiple testing corrections for false discovery rate (FDR) were used. The FDR-adjusted $P$ value was set to less than .05 , and transcripts were filtered on the basis of 1.8 -fold or greater difference.

\section{Functional Annotation and Network Analysis}

Differentially expressed genes were analyzed according to predefined pathways and functional categories annotated by Kyoto Encyclopedia of Genes and Genomes and Gene Ontology by using the Database for Annotation, Visualization, and Integrated Discovery bioinformatics resource. ${ }^{12}$ For an overrepresented Gene Ontology or Kyoto Encyclopedia of Genes and Genomes pathway, cutoff $P$ values of .01 and .05 have been selected for the downregulated and upregulated genes, respectively. For Tables E1 and E2, all gene annotations were checked by using online tools and databases: Entrez Gene (www.ncbi.nlm.nih.gov/sites/entrez). The software PathwayStudio (Ariadne, Rockville, Md) and the ResNet database were used to explore the networks of interactions in which the physiologically regulated genes are potentially involved.

\section{Immunohistochemistry and Western Blotting}

Right ventricular specimens were fixed in $4 \%$ paraformaldehyde, washed in PBS, and embedded in paraffin, and $4-\mu \mathrm{m}$ sections were obtained. Immunohistochemistry was performed with the ABC-Kit from DakoCytomation (Glostrup, Denmark). Photos were taken at $40 \times$ magnification. 
Western blotting was performed as previously described. ${ }^{13}$ Statistical analysis (unpaired $t$ test) was carried out with Instat 3 software (GraphPad Software, Inc, La Jolla, Calif), and a $P$ value was calculated for comparison.

\section{Enzyme-Linked Immunosorbent Assay Protein Analysis}

Blood was collected from all patients before surgical intervention, and plasma was separated and stored at $-80^{\circ} \mathrm{C}$. Human TRAIL levels were measured in plasma samples by using the Diaclone enzyme-linked immunosorbent assay (ELISA) kit. Each sample was performed in duplicate. Statistical analysis (unpaired $t$ test) was carried out with Instat 3 software, and a $P$ value was calculated for comparison.

\section{Statistical Analysis}

For the clinical data, continuous variables were summarized by using means and standard deviations (or medians and interquartiles range if the distribution was skewed), and categorical data were summarized as numbers and percentages. Differences between groups were compared by using the $\chi^{2}$ test for categorical variables and the $t$ or Wilcoxon rank sum tests, as appropriate, for continuous variables.

\section{RESULTS}

Clinical data are summarized in Table 1 . The 2 groups were comparable in terms of age, weight, and crossclamp time. There were no deaths and no major morbidity in both groups. One patient in the cyanotic group required a pacemaker but regained sinus rhythm at follow-up. One patient in the acyanotic group required another run of CPB to resect more muscle from the right ventricular outflow tract after the first procedure. Echocardiographic analysis at discharge did not show any significant residual gradient across the right ventricular outflow tract (mean velocity $<3 \mathrm{~m} / \mathrm{s}$ in both groups) or residual ventricular septal defects. CPB time was longer in the cyanotic group, who required more extensive transannular patching and reconstruction of the pulmonary artery compared with the acyanotic patients. Cyanotic patients had longer inotropic support, ventilation time, and intensive care and hospital stays compared with the acyanotic group.

\section{Gene Microarray Analysis}

Analysis of differentially expressed genes. We have used the Affymetrix GeneChip Human Genome U133 Plus 2.0 Array in this study because it represents the most comprehensive whole human genome expression array, providing coverage of more than 47,000 well-substantiated human genes (www.affymetrix.com). Of the genes examined, 795 were identified as differentially expressed in cyanotic versus acyanotic heart biopsy specimens $(P<.05, t$ test followed by Benjamini and Hochberg FDR correction), with $198 \quad(25 \%)$ upregulated and $597 \quad(75 \%)$ downregulated by more than 1.8-fold (Figure 1, A, and Tables E1 and E2). Genes identified as upregulated or downregulated beyond 1.8-fold unmasked overrepresented biologic process in each gene set (Figure 1, $B$ and $C$ ). Myocardial contractility and function, as identified by means of
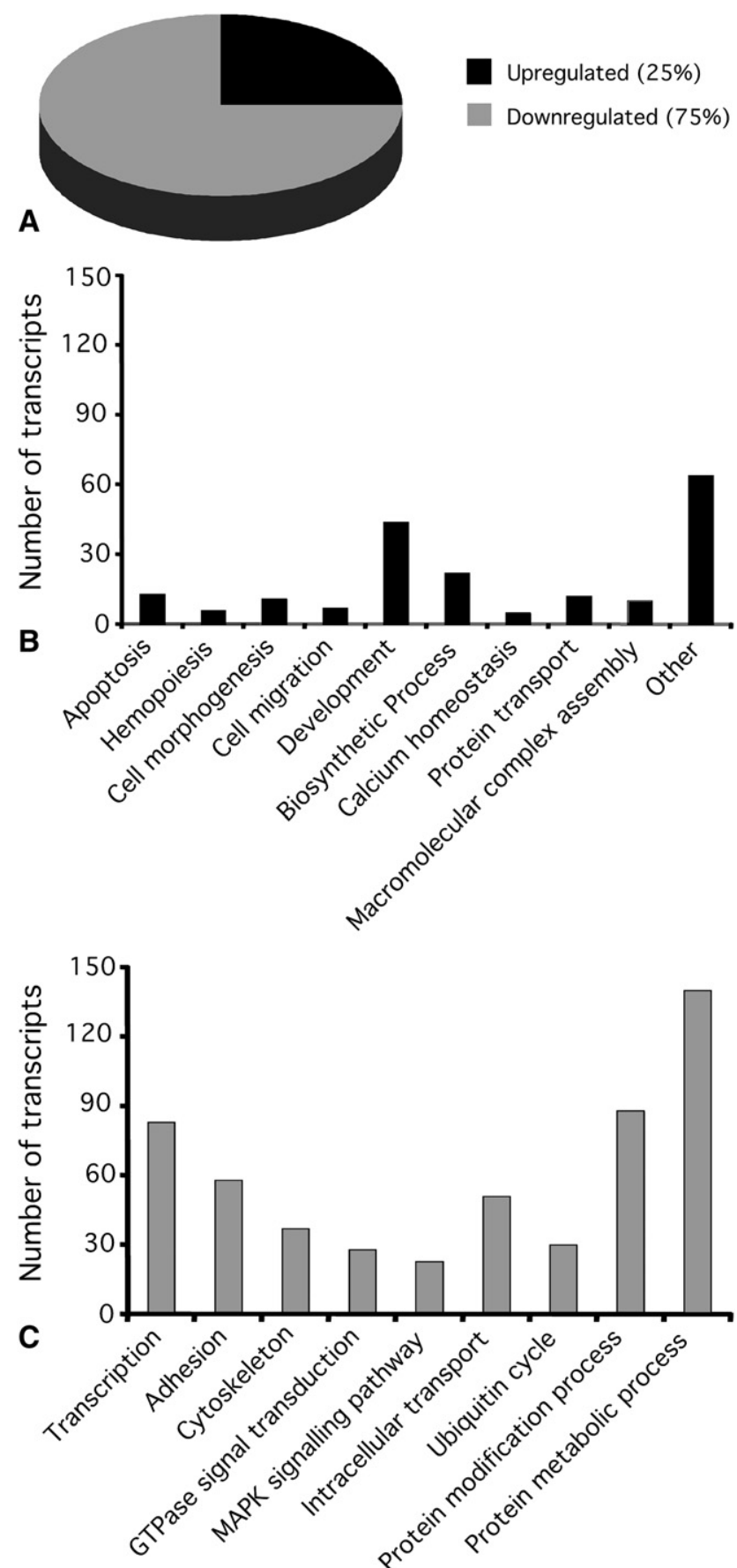

FIGURE 1. Enrichment analysis of functional groups within the genes differentially expressed in cyanotic compared with acyanotic patients. A, Pie chart of the regulated genes in cyanotic compared with acyanotic patients ( $\geq 1$.8-fold). Three quarters of the genes were downregulated and a quarter were upregulated. B and C, Selected GO annotations of genes upregulated (B) and downregulated (C) in cyanotic patients. The histograms show the distribution of these annotations.

cell adhesion, cytoskeletal organization, transcription regulation, guanosine triphosphatase signal transduction, mitogen-activated protein kinase (MAPK) signaling, and 


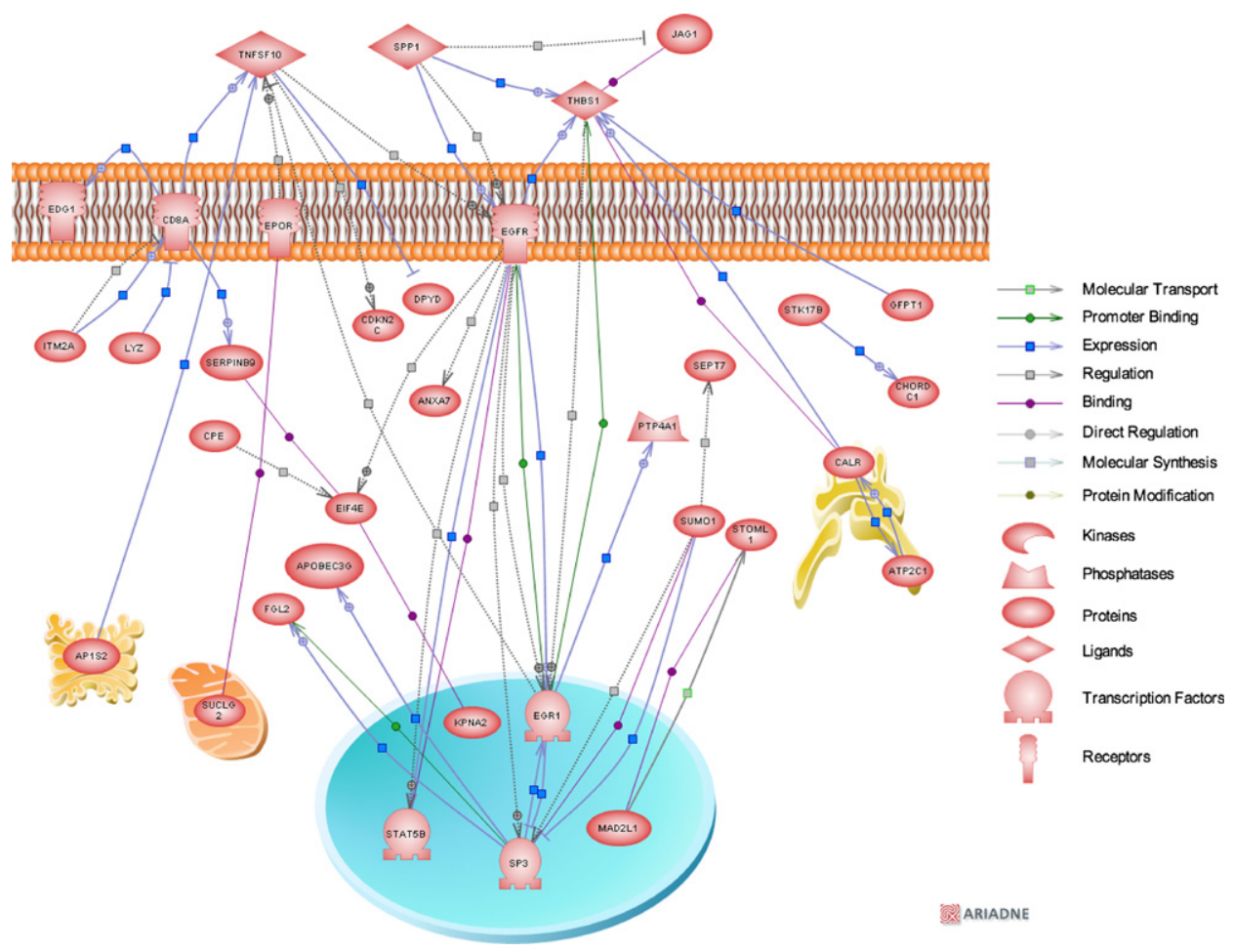

FIGURE 2. Biological association network of the significantly upregulated genes ( $>1.8$-fold) of cyanotic versus acyanotic patient comparisons. The association between the network entities were based on available PubMed citations. Each node in the network map is linked to an html page showing the protein annotation based on available public databases. Small square boxes connecting 2 nodes are linked to an html page showing the type of effect (positive or negative) and the supporting Medline references.

intracellular transport, were downregulated in cyanotic hearts (Figure 1,C). Upregulated transcripts functionally overrepresented apoptosis, cell movement, morphogenesis, and development (Figure 1, B). Collectively, these changes indicate genetic remodeling of the cyanotic myocardium in response to chronic hypoxia.

Pathway analysis. Using Pathway Studio software (Ariadne), we further analyzed the differentially expressed genes (cyanotic vs acyanotic). The analysis looked for the direct pathways connecting genes. For the upregulated genes, the resulting biological association networks are presented in Figure 2. Interestingly, the upregulated genes spanned almost all the cellular organelles. Analysis of downregulated genes associated with the ontological "regulation of transcription" and "MAPK signaling pathway" classes were composed of 83 and 23 downregulated genes, respectively. Of these, 38 and 18 genes, respectively, integrated into direct biological association networks (Figure 3), whereas 45 and 5 genes did not possess interactions.

Cyanosis increases growth, morphogenesis, and remodeling processes and apoptosis signaling. Increased expression of growth, morphogenesis, and remodeling signaling genes emerged as a dominant functional theme for the upregulated genes. This was evident by the increased expression levels of the growth signaling factors $F G F 7$, $T G F B R 2, E G F R$, and insulin-like growth factor binding pro- tein 7 and the remodeling factors $S P P 1(O P N)$ and ACTL6A (Table E1 and Figure 2).

Another dominant functional theme for the upregulated genes was apoptosis. Indeed, our data showed increased expression levels of genes involved in apoptosis signaling, such as TNFSF10 (TRAIL), B-cell chronic lymphocytic leukemia/lymphoma 10 (BCL10), STAT5B, GULPI (CED6), and STK17B (DRAK2; Table E1 and Figure 2).

Cyanosis reduces transcription, MAPK signaling, and contractile machinery. One of the dominant functional classes for the downregulated genes was transcription. The transcription factors that showed a reduction of expression levels included JUN, JUND, ATF2, STAT3, GATA4, EPAS1, NCOA2, ARNT, and SP1 (Table E2 and Figure 3, $A$ ).

Reduction of MAPK signaling genes emerged as another important functional theme for the downregulated genes. This was evident by the decreased expression levels of MAPK1 (ERK), MAPK14 (SAPK2), MAP3K2, MAP3K3, MAP4K4, AKT2, TAOK1, SOS1, and SOS2 (Table E2 and Figure $3, B$ ). In addition, our data exhibited a downregulation in the contractile machinery (cytoskeleton and cell-adhesion clusters). The downregulated transcripts included troponin $\mathrm{T}$ type 2, myosin XVIIIB, ARP2 actinrelated protein 2 and nebulin-related anchoring protein (Figure E1). 

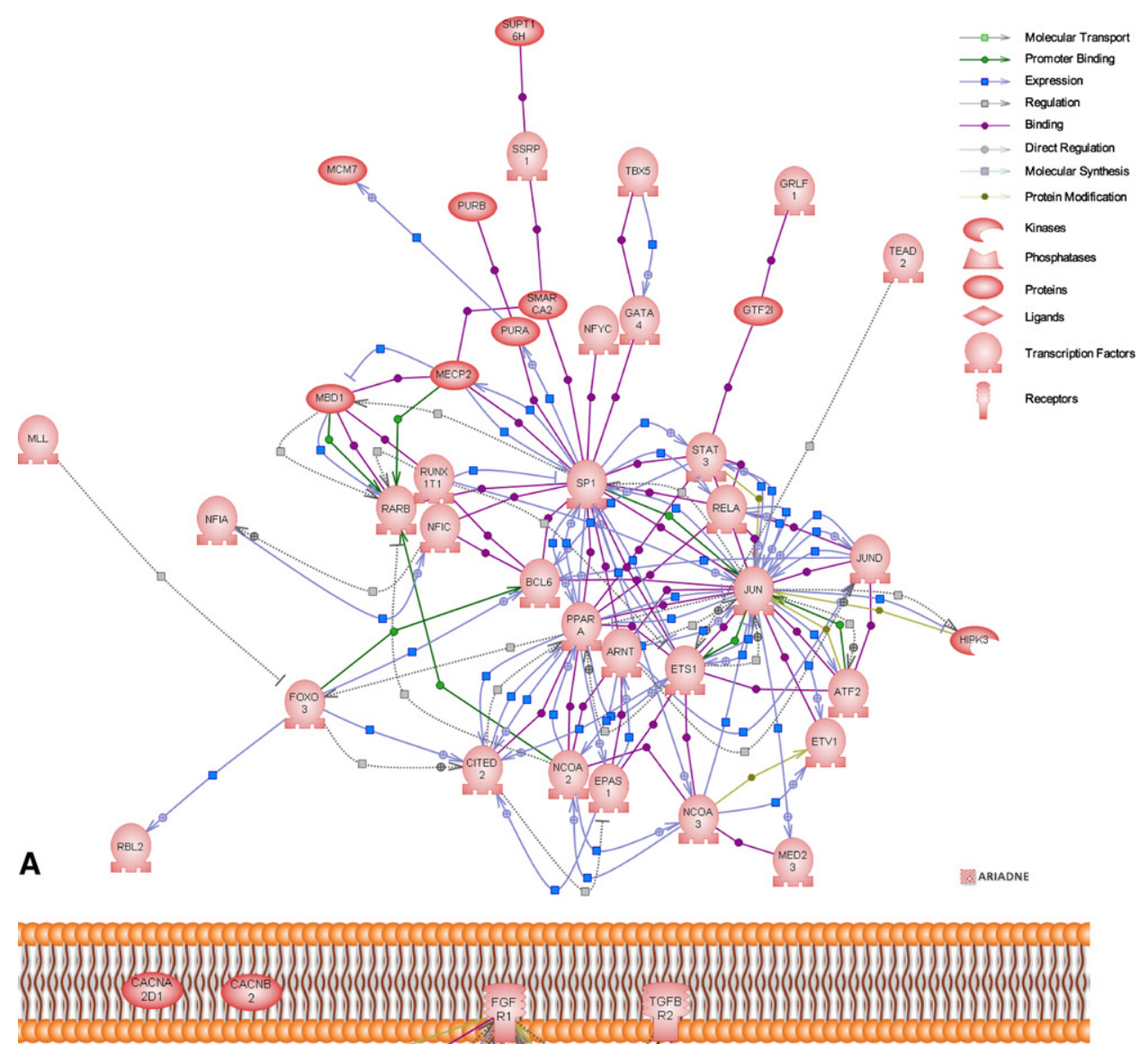

B

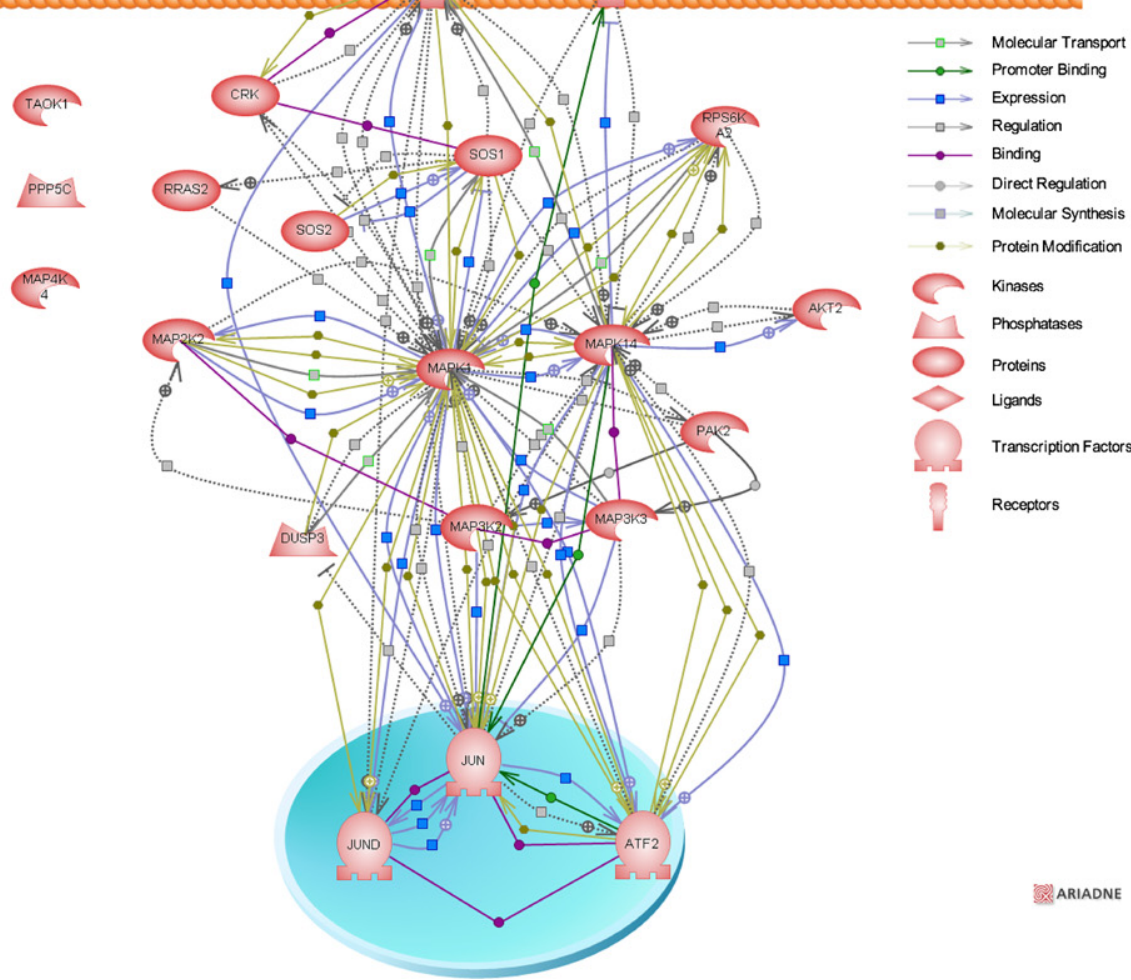

FIGURE 3. Biological association networks of the significantly downregulated genes associated with the ontological "regulation of transcription" (A) and "MAPK signaling pathway" (B) classes. Each node in network maps is linked to an html page showing the protein annotation based on available public databases. Small square boxes connecting 2 nodes are linked to an html page showing the type of effect (positive or negative) and the supporting Medline references. 


\section{Validation of Differential Expression of Selected Gene Products}

Despite being greatly informative, changes in mRNA levels are insufficient to predict protein expression levels. We therefore went onto assessing the protein levels of the identified genes in the myocardium and blood of cyanotic and acyanotic children using immunohistochemistry, Western blotting, and ELISA. By using immunohistochemistry, we showed COX11, NCX1, OPN, TRAIL, and LYZ protein immunostaining in the myocardium of cyanotic and acyanotic children (Figures E2, $C$ and $D$; E3, $A$ and $B$, E4, $C$ and $D$; and $\mathrm{E} 5, A$ and $B$ ). The strongest signals observed were those of COX11 and LYZ. Subsequently, we semiquantitatively assessed protein level changes in the myocardium of cyanotic and acyanotic children by using Western blotting. COX11, OPN, and LYZ showed significant increases in cyanotic samples compared with levels seen in acyanotic samples (Figures E2, $E$ and $F$; E5, $C$ and $D$; and E6, $C$ and $D$ ), which is similar to that observed at the mRNA level. NCX1 protein levels showed a significant decrease caused by cyanosis (Figure E3, $C$ and $D$ ), resembling that obtained at the transcriptomic level. In contrast, TRAIL protein levels showed no alteration in the myocardium of the 2 groups of patients (Figure E4, $A$ and $B$ ). Because TRAIL is a soluble protein that could be released in blood, we assessed TRAIL plasma levels by means of ELISA. Our data indicated a significant $42 \%$ increase of TRAIL plasma levels in cyanotic compared with acyanotic children (Figure E4, E).

\section{Functional Validation}

To functionally validate our transcriptomics-derived hypothesis, we examined protein expression levels of markers of hypoxia, apoptosis, and MAPK signaling activation in myocardial tissue. Western blotting of hypoxia-inducible factor 1 alpha showed a significant upregulation in cyanotic compared with acyanotic tissue, confirming the hypoxic state this patient group's experiences (Figure E7, A). Additionally, we showed a significant increase in cleaved caspase-3 (activated form) and Bcl-2-associated X protein (BAX) protein expression in cyanotic compared with acyanotic myocardium (Figure E7, $B$ and $C$ ). Caspase- 3 is a critical apoptosis executioner, and BAX is a well-documented apoptotic activator. Increased levels of cleaved caspase-3 and BAX in cyanotic myocardium indicate an increased apoptotic activity in the hearts of these patients. Furthermore, we showed a significant decrease in phosphoSAPK (activated form) expression levels in cyanotic compared with acyanotic myocardium (Figure E7, D). We also detected a tendency toward a decrease in phosphorylated extracellular signal-regulated kinase (ERK) levels in cyanotic myocardium, although it was not significant (data not shown).

\section{DISCUSSION}

The results of this microarray-based gene expression profiling study seem to confirm the existence of a reprogramming response that is most evident in the chronically hypoxic cyanotic myocardium. Growth/morphogenesis, remodeling, and apoptosis emerged as dominant functional themes for the upregulated genes (Figures 1 and 2). In contrast, transcription, MAPK signaling, and contractile machinery (cytoskeleton and adhesion) were the dominant functional classes for the downregulated genes (Figures 1 and 3).

Previous studies have shown RVH in patients with TOF compared with that seen in healthy control subjects. ${ }^{7,10}$ These studies did not differentiate between cyanotic and acyanotic TOF. Our clinical data did not indicate a higher $\mathrm{RVH}$ in cyanotic patients, suggesting that the observed transcriptomic changes are mainly related to cyanosis. In our investigation the expression level changes of extracellular matrix factors (remodeling markers) in cyanotic compared with acyanotic patients went in both directions. Indeed, levels of FBLNI and SPP1, for example, increased in cyanotic patients, whereas levels of COL3Al, COL4A1, COLAA2, COL6A1, COLA6A2, and COL12A1 decreased (Figure E8). Increased levels of collagen I and III have been shown to be associated with RV remodeling. ${ }^{10}$ It is tempting to speculate that the right ventricle remodels differently in cyanotic and acyanotic patients, with more injury-related reprogramming occurring in cyanotic patients. However, in the absence of gene expression data from age-matched healthy control subjects, we are unable to validate such a hypothesis.

Our data showed increased gene expression levels of the growth-signaling factors $F G F 7, T G F B R 2$, EGFR, and insulin-like growth factor binding protein 7 (Table E1 and Figure 2). These gene expression changes could be attributed to a myocardial survival program in an attempt at protecting itself from hypoxia-related cell damage. It is documented that growth factors mediate the survival response in many cell types, ${ }^{14}$ and the activation of growth factor signaling is cardioprotective. ${ }^{15}$ A previous study showed an increased expression level of VEGF in the right ventricle when comparing patients with TOF with healthy control subjects. ${ }^{10}$ Our findings showed no changes in VEGF expression levels in cyanotic compared with acyanotic patients.

Additionally, our data showed increased apoptosis in cyanotic myocardium and increased expression of apoptosis signaling genes, such as TNFSF10 (TRAIL), B-cell chronic lymphocytic leukemia/lymphoma 10 (BCL10), STAT5B, GULP1 (CED6), and STK17B (DRAK2; (Table E1 and Figure 2). The protein encoded by BCL10 (CARMEN) contains a caspase recruitment domain and has been shown to induce apoptosis and to activate nuclear factor $\kappa \mathrm{B} .{ }^{16}$ The protein encoded by $S T A T 5 B$, a member of the signal transducer and activator of transcription family of transcription factors, has been shown to be involved in diverse biological 
processes, including apoptosis. ${ }^{17}$ GULP1 is an evolutionarily conserved adaptor protein required for efficient engulfment of apoptotic cells by phagocytes. ${ }^{18}$ DRAK2 is a member of the death-associated protein kinase family capable of inducing apoptosis on overexpression in cell culture. ${ }^{19}$ The activation of apoptosis signaling illustrates how the chronic hypoxic stress seems to promote an injury program within cyanotic patients' myocardium. This program might explain the worst reoxygenation injury that cyanotic patients experience during and after corrective heart surgery. ${ }^{4}$

Transcription, MAPK signaling, and contractile machinery (cytoskeleton and adhesion) were the important functional classes for the downregulated genes (Figures 1 and 3). Three of the identified downregulated transcription factors, JUND, JUN, and ATF2, are players in both transcription and MAPK signaling direct association networks (Figure 3). Other downregulated transcription factors included STA3, GATA4, EPAS1, ARNT, NCOA2, and SP1. The reduction of transcription represents part of the injuryrelated program initiated by chronic hypoxia. Indeed, fully functional transcription machinery is crucial for myocardial function and survival, and a decrease in transcription factor levels would have a repercussion on cardiac function and survival.

Similarly, the reduction of MAPK signaling is another component of the injury-related program triggered by chronic hypoxia. Indeed, the MAPK pathway is crucial for myocyte survival and function. Decreased expression levels of key players of this pathway (eg, activated SAPK) could have a serious effect on the myocardium. Examples of the MAPK pathway players that showed decreased expression levels are MAPK1 (ERK), MAPK14 (SAPK2), MAP3K2, MAP $3 K 3$, MAP4K4, AKT2, TAOK1, SOS1, and SOS2 (Table E2 and Figure 3, $B$ ). MAPKs phosphorylate a number of known transcription factors to alter their transactivating activities, thus presumably influencing gene expression to elicit the cellular response. ${ }^{20}$ In cardiac myocytes members of the ERK MAPK family have been implicated in survival signaling in response to ischemia and reperfusion, oxidative stress, and hypoxia. ${ }^{21}$ Other studies have also shown that the MAPK/ERK kinase and phosphoinositide 3-kinase-protein kinase Akt/protein kinase B pathways might protect against apoptosis. ${ }^{14}$

In addition, our study showed a downregulation in the contractile machinery (cytoskeleton and cell adhesion clusters). The downregulated transcripts belonging to this grouping included troponin T type 2, myosin XVIIIB, ARP2 actin-related protein 2 , and nebulin-related anchoring protein. The reduction of contractile machinery factors seems to represent another part of the injury-related program initiated by cyanosis. Such alteration of contractility factor levels could explain the susceptibility of cyanotic patients to reoxygenation injury (Figure E1).

\section{COX11}

Cytochrome-c oxidase 11 (COX11) showed important upregulation in cyanotic patients at the mRNA and protein levels. The COX11 protein is a constituent of the inner mitochondrial membrane and might be involved in biosynthesis of heme A. The upregulation of COX11 in our study suggests that the cyanosis state might trigger a compensation mechanism through COX11 and copper transport to palliate the lack of oxygen.

\section{NCX1}

The sodium-calcium $\left(\mathrm{Na}^{+}-\mathrm{Ca}^{2+}\right)$ exchanger (NCX1, SLC8A1) showed an important downregulation in cyanotic patients at both the mRNA and protein levels. NCX1 is a membrane protein that is considered to play an important role in the $\mathrm{Ca}^{2+}$ handling of cardiac myocytes. The observed NCX1 downregulation could decrease myocyte calcium handling capacity, leading to mechanical dysfunction.

\section{TRAIL}

TNFSF10 (TRAIL) showed also important upregulation in cyanotic patients. TRAIL is a cytokine that belongs to the tumor necrosis factor ligand family. The binding of this protein to its receptors has been shown to trigger the activation of MAPK8/c-Jun NH2-terminal kinase, caspase-8, and caspase- 3 , thus inducing apoptosis. ${ }^{22}$ The observed TRAIL increase in the circulation of cyanotic patients could emanate from the myocardium. TRAIL increases in the circulation of cyanotic patients could induce apoptosis in organs and tissues expressing TRAIL receptors. The activity of this protein might be modulated by binding to decoy receptors that cannot induce apoptosis. These decoy receptors, such as osteoprotegerin, present great potential for use as a therapy to reduce any TRAIL induced-apoptosis.

\section{SPP1}

SPP1, also known as osteopontin (OPN), was upregulated by 2 -fold in cyanotic patients at the mRNA and protein levels. OPN is expressed in the heart at low levels under normal conditions. ${ }^{23}$ Although the exact role of OPN in cardiomyocyte function is unknown, there is evidence that cardiomyocytes are a prominent source of OPN in vivo and that induction of OPN expression is strongly associated with ventricular remodeling. ${ }^{24}$ Additionally, increase of OPN expression in the myocardium coincides with the development of heart failure. ${ }^{25}$ Our data showed an increase in OPN expression at the mRNA and protein levels in cyanotic children, suggesting a remodeling program initiated by chronic hypoxia in the myocardium.

\section{LYZ}

LYZ (lysozyme) showed the highest upregulation (5:1) in cyanotic patients. LYZ, the natural substrate of which is 
bacterial cell wall peptidoglycan, is one of the antimicrobial agents found in human milk and is also present in the spleen, lung, kidney, white blood cells, plasma, saliva, and tears. Here we show protein expression of the LYZ gene product in the ventricular myocardium and increased levels in cyanotic compared with acyanotic patients. The biological significance of this increase is not known, and further studies would be required to uncover it.

\section{Limitations}

Even though there was no difference between the 2 groups in terms of right ventricular wall thickness, one cannot completely exclude the possibility that RVH could be a potential confounder in our findings.

As expected, there was a difference in the 2 groups regarding the preoperative use of $\beta$-blockers, and this might be a potential confounding factor because it might influence the course of RVH and remodeling.

We did not study normal or nondiseased right ventricular myocardium; however, our focus was on the gene expression differences between cyanotic and acyanotic patients with TOF.

Finally, our investigation can be interpreted as a descriptive study that generates more hypotheses. However, it is our belief that this will provide a better understanding of the mechanisms associated with chronic hypoxia and help develop interventions aimed at improving the clinical outcome in this high-risk group of patients.

\section{CONCLUSIONS}

Overall, the transcriptional profile in the cyanotic group was characterized by increased expression level of genes with literature-validated apoptosis and growth/morphogenesis/remodeling properties. Furthermore, it showed decreased expression levels of genes with cardiac function, cell survival, and cytoprotective properties. The molecular signatures identified suggest a reprogramming response in the cyanotic myocardium activated by the chronic hypoxia imposed by the structural congenital heart disease.

\section{CLINICAL IMPLICATIONS}

In this study patients in both groups (cyanotic and acyanotic TOF) exhibited a significant hypertrophy of the right ventricle caused by pressure overload. In cyanotic patients the higher degree of right ventricular obstruction and the smaller size of the pulmonary annulus and main pulmonary artery were responsible for the preoperative chronic hypoxic state. We therefore believe that these 2 groups of patients constitute the best possible model to study the influence of cyanosis on gene expression. Our analysis identified several genes deregulated in the cyanotic heart that might be responsible for the susceptibility of cyanotic children to ischemia and reoxygenation injury during and after surgical intervention. Indeed, our previous data ${ }^{4,5}$ showed that cyanotic patients have significant perioperative myocardial cell damage compared with acyanotic patients undergoing cardiac surgery. This susceptibility to ischemia and reperfusion damage can be explained by the impairment of factors crucial to cardiac function, induction of apoptotic pathways, and alteration of signal transduction pathways seen in cyanotic patients in this study. This information might have a significant effect in improving surgical strategies in cyanotic patients with TOF undergoing corrective cardiac surgery.

We thank Professors Murphy, Newby, and Suleiman for their valuable comments. We also acknowledge Mr A. Parry and Mrs C. McFadden for his surgical and her secretarial help and Megan Musson for her technical assistance.

\section{References}

1. Ihnken K, Morita K, Buckberg GD, Matheis G, Sherman MP, Allen BS, et al. Studies of hypoxemic/reoxygenation injury: without aortic clamping. II. Evidence for reoxygenation damage. J Thorac Cardiovasc Surg. 1995;110:1171-81.

2. Teoh KH, Mickle DA, Weisel RD, Li RK, Tumiati LC, Coles JG, et al. Effect of oxygen tension and cardiovascular operations on the myocardial antioxidant enzyme activities in patients with tetralogy of Fallot and aorta-coronary bypass. J Thorac Cardiovasc Surg. 1992;104:159-64.

3. Dhaliwal H, Kirshenbaum LA, Randhawa AK, Singal PK. Correlation between antioxidant changes during hypoxia and recovery on reoxygenation. Am J Physiol Heart Circ Physiol. 1991;261:H632-8.

4. Imura H, Caputo M, Parry A, Pawade A, Angelini GD, Suleiman MS. Age-dependent and hypoxia-related differences in myocardial protection during pediatric open heart surgery. Circulation. 2001;103:1551-6.

5. Modi P, Imura H, Caputo M, Pawade A, Parry A, Angelini GD, et al. Cardiopulmonary bypass-induced myocardial reoxygenation injury in pediatric patients with cyanosis. J Thorac Cardiovasc Surg. 2002;124:1035-6.

6. del Nido PJ, Mickle DA, Wilson GJ, Benson LN, Coles JG, Trusler GA, et al. Evidence of myocardial free radical injury during elective repair of tetralogy of Fallot. Circulation. 1987;76(suppl):V174-9.

7. Kaynak B, von Heydebreck A, Mebus S, Seelow D, Hennig S, Vogel J, et al. Genome-wide array analysis of normal and malformed human hearts. Circulation. 2003; 107:2467-74.

8. Konstantinov IE, Coles JG, Boscarino C, Takahashi M, Goncalves J, Ritter J, et al. Gene expression profiles in children undergoing cardiac surgery for right heart obstructive lesions. J Thorac Cardiovasc Surg. 2004;127:746-54.

9. Arab S, Konstantinov IE, Boscarino C, Cukerman E, Mori A, Li J, et al. Early gene expression profiles during intraoperative myocardial ischemia-reperfusion in cardiac surgery. $J$ Thorac Cardiovasc Surg. 2007;134:74-81, e1-2.

10. Sharma HS, Peters TH, Moorhouse MJ, van der Spek PJ, Bogers AJ. DNA microarray analysis for human congenital heart disease. Cell Biochem Biophys. 2006;44:1-9.

11. Hindmarch C, Yao S, Beighton G, Paton J, Murphy D. A comprehensive description of the transcriptome of the hypothalamoneurohypophyseal system in euhydrated and dehydrated rats. Proc Natl Acad Sci U S A. 2006;103:1609-14.

12. Dennis G Jr, Sherman BT, Hosack DA, Yang J, Gao W, Lane HC, et al. DAVID: Database for Annotation, Visualization, and Integrated Discovery. Genome Biol. 2003;4:P3.

13. Ghorbel MT, Sharman G, Leroux M, Barrett T, Donovan DM, Becker KG, et al. Microarray analysis reveals interleukin-6 as a novel secretory product of the hypothalamo-neurohypophyseal system. J Biol Chem. 2003;278:19280-5.

14. Bishopric NH, Andreka P, Slepak T, Webster KA. Molecular mechanisms of apoptosis in the cardiac myocyte. Curr Opin Pharmacol. 2001;1:141-50.

15. Hausenloy DJ, Yellon DM. New directions for protecting the heart against ischaemia-reperfusion injury: targeting the reperfusion injury salvage kinase (RISK)-pathway. Cardiovasc Res. 2004;61:448-60.

16. Wang D, You Y, Lin PC, Xue L, Morris SW, Zeng H, et al. Bcl10 plays a critical role in NF-kappaB activation induced by G protein-coupled receptors. Proc Natl Acad Sci U S A. 2007;104:145-50. 
17. Joung YH, Lim EJ, Kim MS, Lim SD, Yoon SY, Lim YC, et al. Enhancement of hypoxia-induced apoptosis of human breast cancer cells via STAT5b by momilactone B. Int J Oncol. 2008;33:477-84.

18. Su HP, Nakada-Tsukui K, Tosello-Trampont AC, Li Y, Bu G, Henson PM, et al. Interaction of CED-6/GULP, an adapter protein involved in engulfment of apoptotic cells with CED-1 and CD91/low density lipoprotein receptor-related protein (LRP). J Biol Chem. 2002;277:11772-9.

19. Kogel D, Prehn JH, Scheidtmann KH. The DAP kinase family of pro-apoptotic proteins: novel players in the apoptotic game. Bioessays. 2001;23:352-8.

20. Yang SH, Sharrocks AD, Whitmarsh AJ. Transcriptional regulation by the MAP kinase signaling cascades. Gene. 2003;320:3-21.

21. Baines CP, Molkentin JD. STRESS signaling pathways that modulate cardiac myocyte apoptosis. J Mol Cell Cardiol. 2005;38:47-62.
22. Muhlenbeck F, Haas E, Schwenzer R, Schubert G, Grell M, Smith C, et al. TRAIL/Apo2L activates c-Jun NH2-terminal kinase (JNK) via caspasedependent and caspase-independent pathways. J Biol Chem. 1998;273: 33091-8.

23. Subramanian V, Krishnamurthy P, Singh K, Singh M. Lack of osteopontin improves cardiac function in streptozotocin-induced diabetic mice. Am J Physiol Heart Circ Physiol. 2007;292:H673-83.

24. Graf K, Do YS, Ashizawa N, Meehan WP, Giachelli CM, Marboe CC, et al Myocardial osteopontin expression is associated with left ventricular hypertrophy. Circulation. 1997;96:3063-71.

25. Singh K, Sirokman G, Communal C, Robinson KG, Conrad CH, Brooks WW, et al. Myocardial osteopontin expression coincides with the development of heart failure. Hypertension. 1999;33:663-70. 


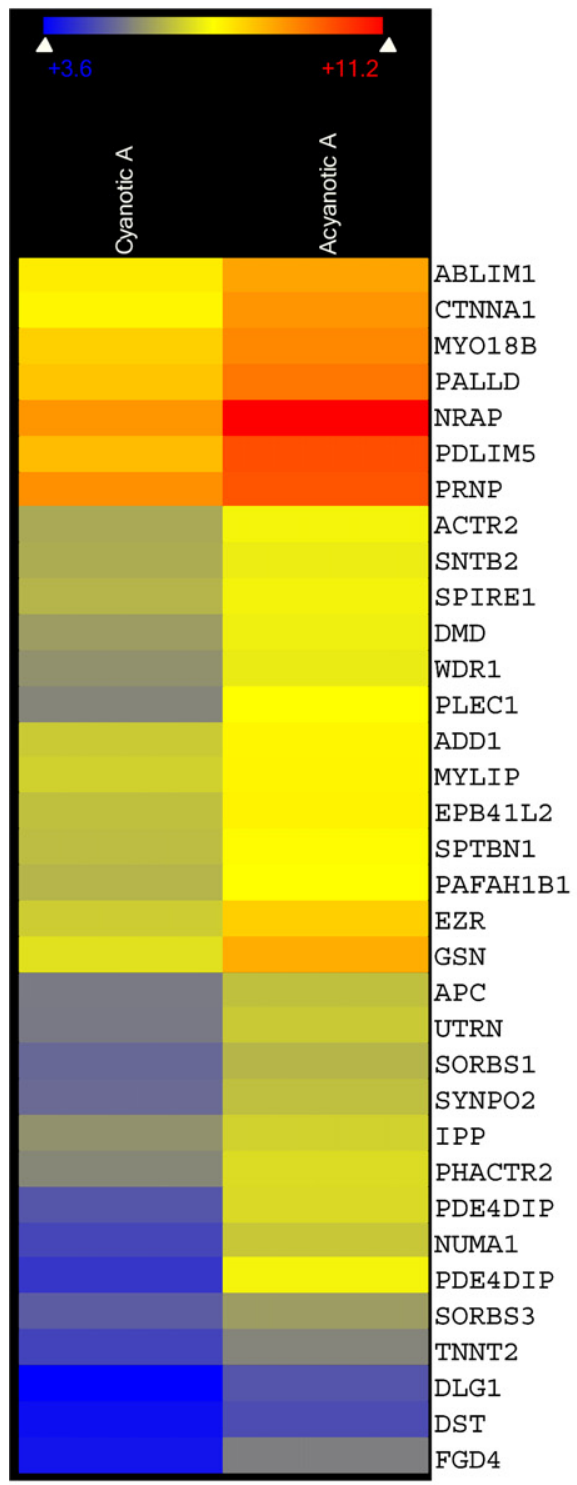

A

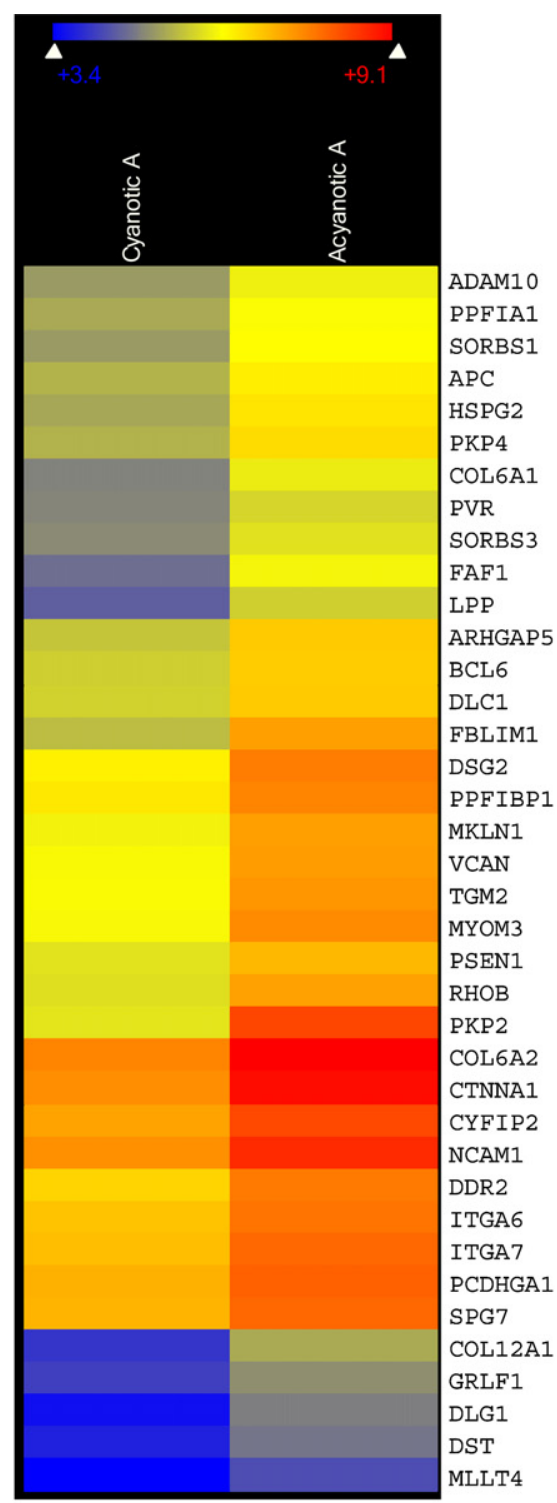

B

Highly suppressed genes

$\square$ Mildly expressed genes

Highly expressed genes

FIGURE E1. Heat Map illustrating the expression levels of contractile machinery genes. A, Cytoskeletal cluster. B, Cell adhesion cluster. Hierarchical clustering has been performed with ArrayStar software. A 3-color scale was used to illustrate expression level differences, with blue indicating low expression values, yellow indicating intermediately expressed genes, and red representing highly expressed genes. 

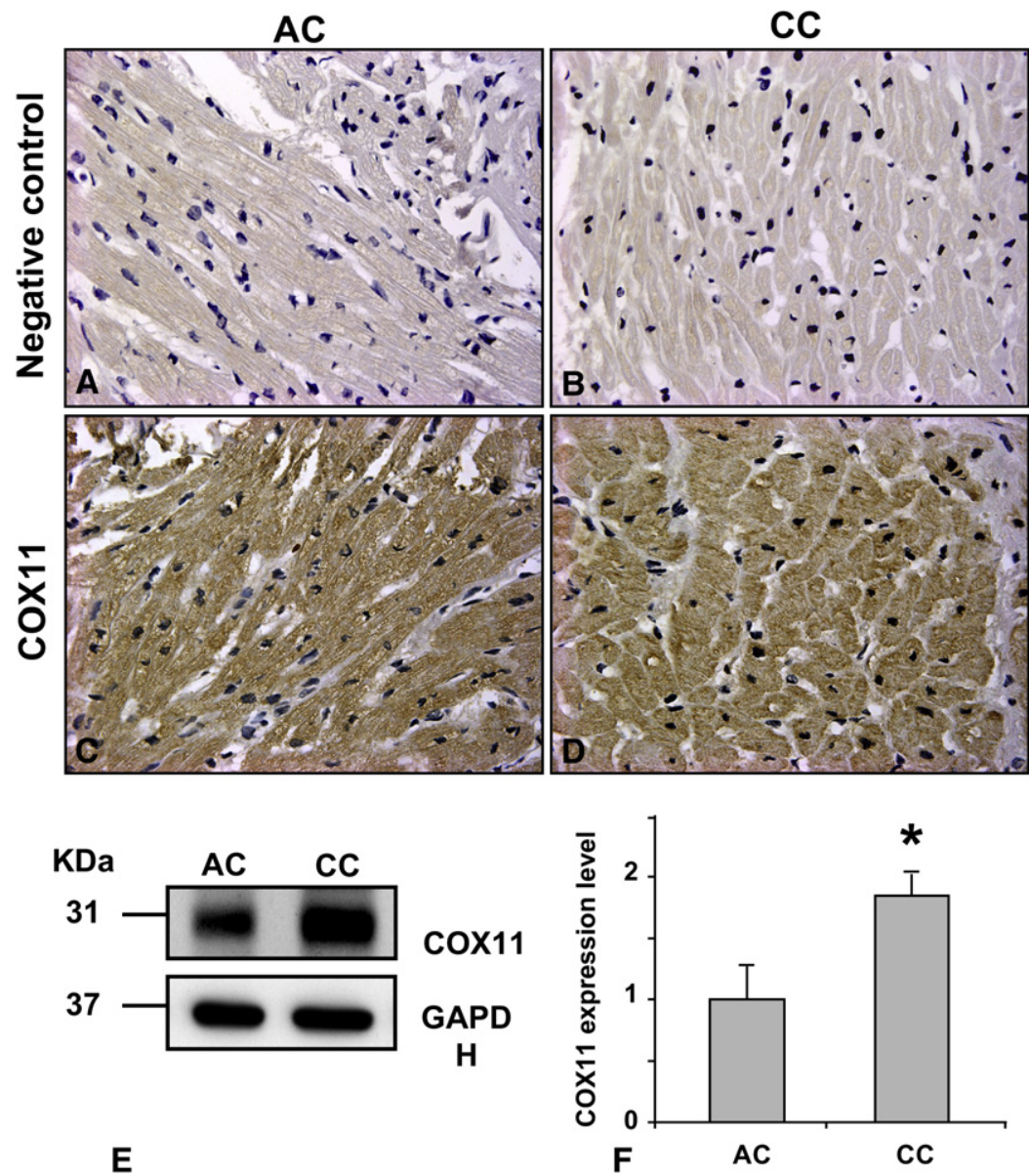

FIGURE E2. COX 11 protein immunostaining of paraffin-embedded heart tissue from acyanotic (C) and cyanotic (D) patients using COX11-specific antibody. 3,3'-Diaminobenzidine (DAB) staining (brown) reveals expression of COX11 in both tissues but not in control tissue (A and B). E and F, COX11 protein expression level in myocardium of acyanotic $(A C)$ and cyanotic $(C C)$ patients. Biopsy specimens were lysed to isolate protein content and Western blotting analysis was performed, probing for COX11 and glyceraldehyde-3-phosphate dehydrogenase (GAPDH). COX11 was significantly upregulated in cyanotic biopsy specimens compared with that seen in acyanotic specimens. COX11 bands were normalized to glyceraldehude-3-phosphate dehydrogenase $(G A P D H)$ levels. Data are presented as means \pm standard errors of the mean. $* P<.05(\mathrm{n}=6)$. 

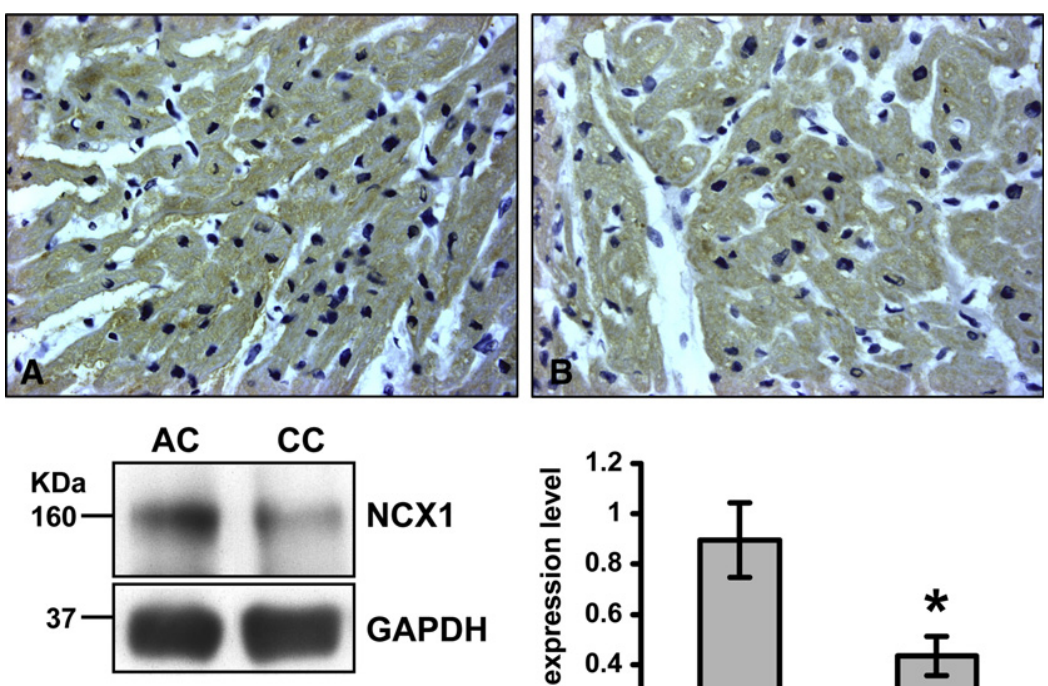

C

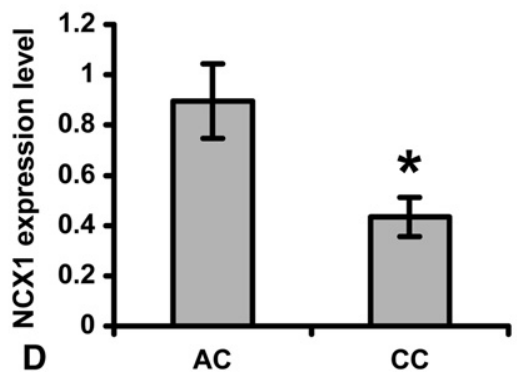

FIGURE E3. A and B, NCX1 protein immunostaining of paraffin-embedded heart tissue from acyanotic (A) and cyanotic (B) patients using NCX1-specific antibody. 3,3'-Diaminobenzidine (DAB) staining (brown) reveals expression of NCX1 in both tissues. C and D, NCX1 protein expression level in myocardium of acyanotic $(A C)$ and cyanotic $(C C)$ patients. Biopsy specimens were lysed to isolate protein content, and Western blotting analysis was performed, probing for NCX1 and glyceraldehude-3-phosphate dehydrogenase (GAPDH). NCX1 was significantly downregulated in cyanotic biopsy specimens compared with acyanotic specimens. NCX1 bands were normalized to GAPDH levels. Data are presented as means \pm standard errors of the mean. $* P<.05$ $(n=4)$. 

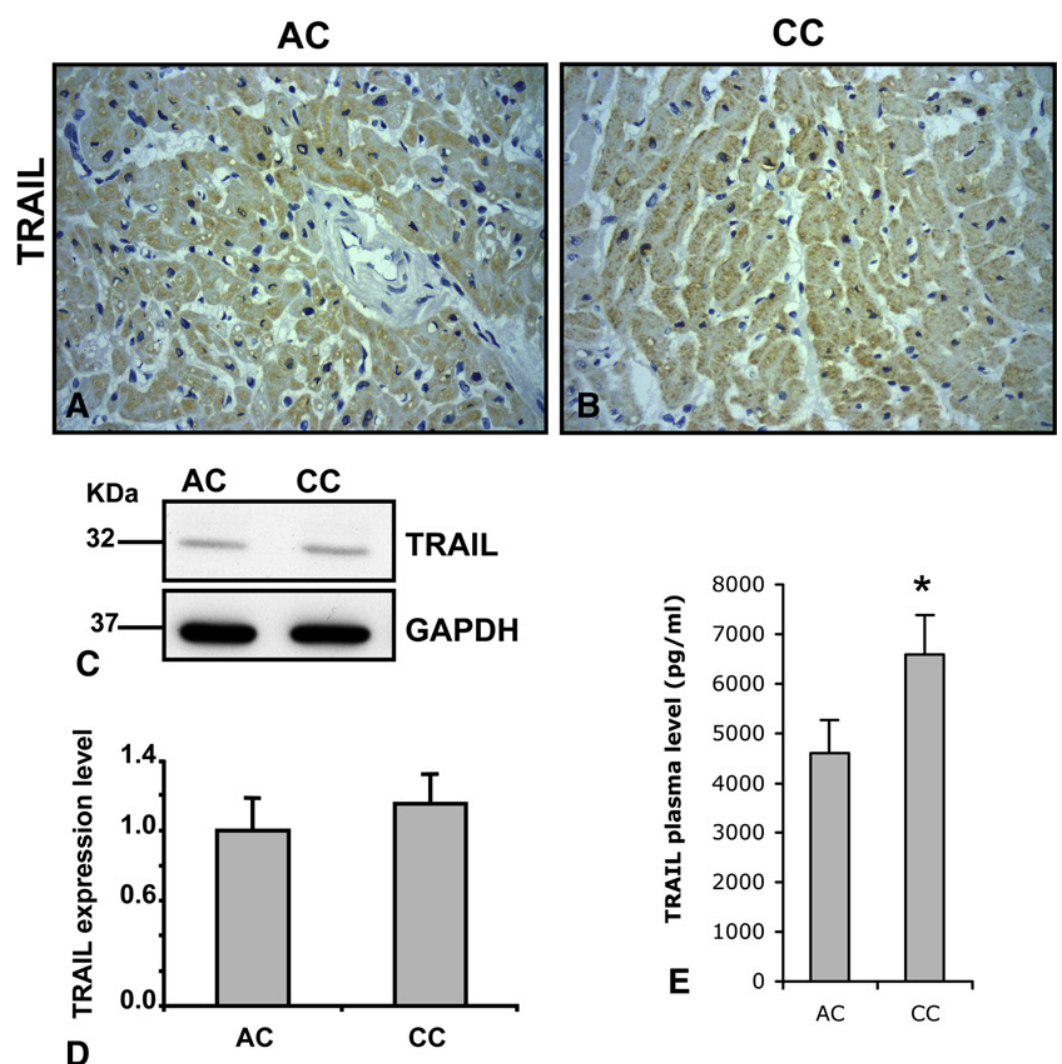

FIGURE E4. TRAIL protein immunostaining of paraffin-embedded heart tissue from acyanotic (A) and cyanotic (B) patients using TRAIL-specific antibody. 3,3'-Diaminobenzidine (DAB) staining (brown) reveals expression of TRAIL in both tissues. C and D, TRAIL protein expression level in myocardium of acyanotic $(A C)$ and cyanotic $(C C)$ patients. Biopsy specimens were lysed to isolate protein content, and Western blotting analysis was performed, probing for TRAIL and glyceraldehude-3-phosphate dehydrogenase (GAPDH). TRAIL was not upregulated in cyanotic biopsy specimens compared with acyanotic specimens. TRAIL bands were normalized to GAPDH levels. Data are presented as means \pm standard errors of the mean $(n=6)$. E, Plasma levels of TRAIL in cyanotic $(C C)$ and acyanotic $(A C)$ children. Solid bars represent median protein concentration in preoperative plasma samples (in picograms per milliliter). A significantly enhanced TRAIL protein expression was observed in cyanotic samples. Data are presented as means \pm standard errors of the mean. $* P<.05$ $(\mathrm{n}=9-11)$ 

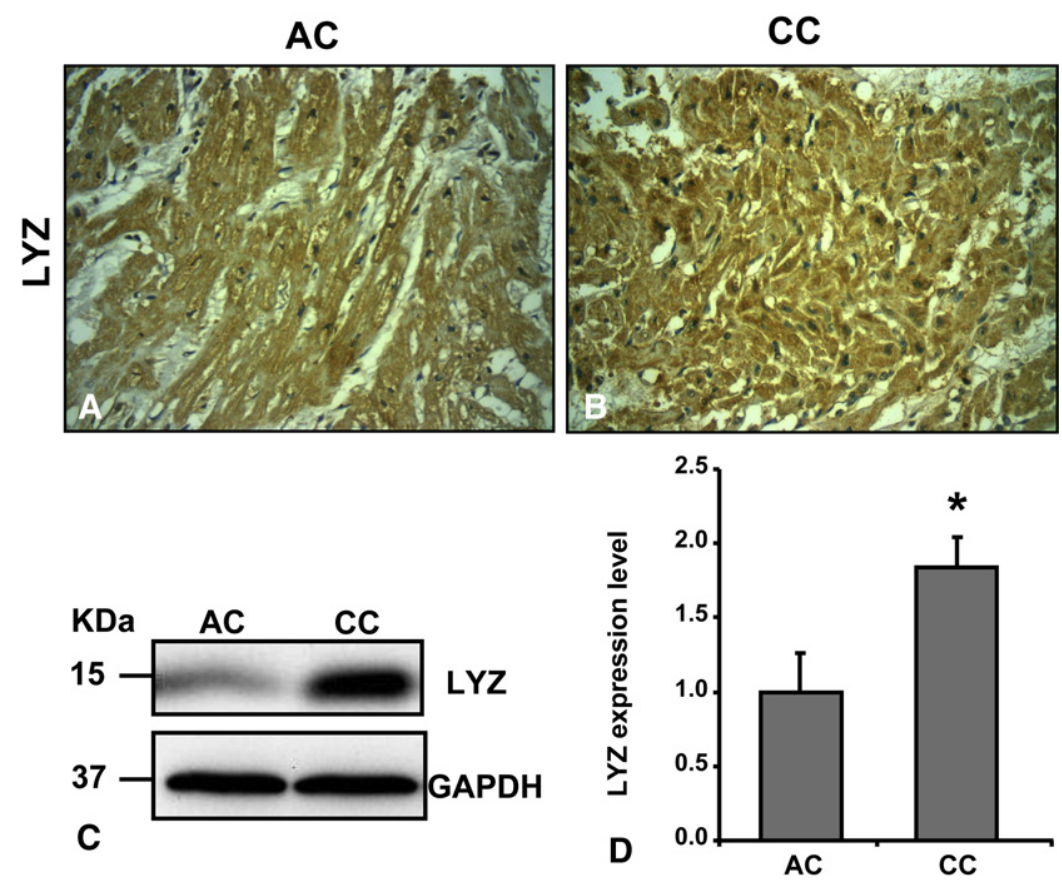

FIGURE E5. LYZ protein immunostaining of paraffin-embedded heart tissue from acyanotic (A) and cyanotic (B) patients using LYZ-specific antibody. 3,3'-Diaminobenzidine (DAB) staining (brown) reveals expression of LYZ in both tissues. C and D, LYZ protein expression level in myocardium of acyanotic $(A C)$ and cyanotic $(C C)$ patients. Biopsy specimens were lysed to isolate protein content, and Western blotting analysis was performed, probing for LYZ and glyceraldehude-3-phosphate dehydrogenase (GAPDH). LYZ was significantly upregulated in cyanotic biopsy specimens compared with acyanotic specimens. LYZ bands were normalized to GAPDH levels. Data are presented as means \pm standard errors of the mean. $* P<.05(n=6)$. 

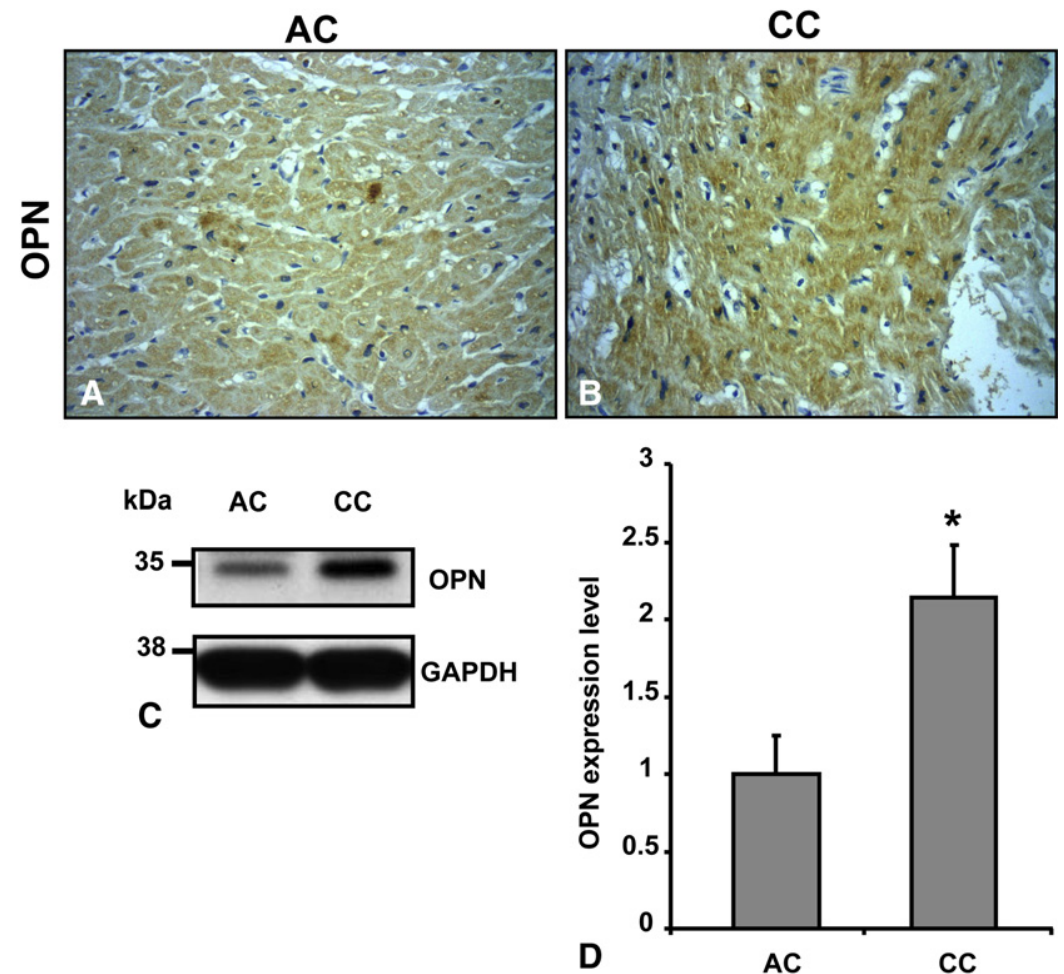

FIGURE E6. OPN protein immunostaining of paraffin-embedded heart tissue from acyanotic (A) and cyanotic (B) patients using OPN-specific antibody. $3,3^{\prime}$-Diaminobenzidine (DAB) staining (brown) reveals expression of OPN in both tissues. C and D, OPN protein expression level in myocardium of acyanotic $(A C)$ and cyanotic $(C C)$ patients. Biopsy specimens were lysed to isolate protein content, and Western blotting analysis was performed, probing for OPN and glyceraldehude-3-phosphate dehydrogenase $(G A P D H)$. OPN was significantly upregulated in cyanotic biopsy specimens compared with acyanotic specimens. OPN bands were normalized to GAPDH levels. Data are presented as means \pm standard errors of the mean. $* P<.05(\mathrm{n}=6)$. 


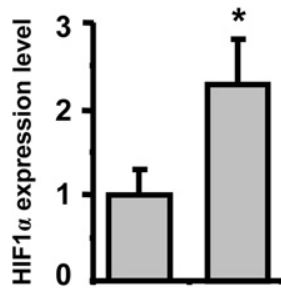

A

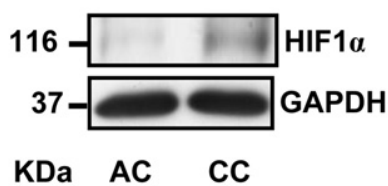

C

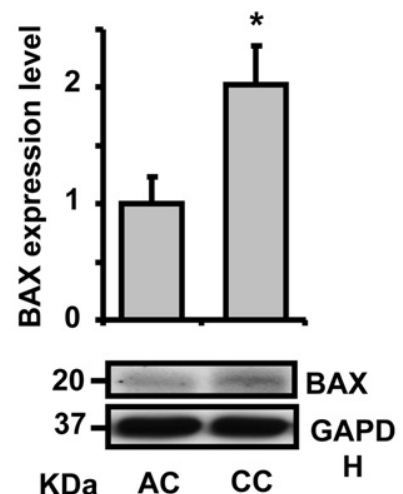

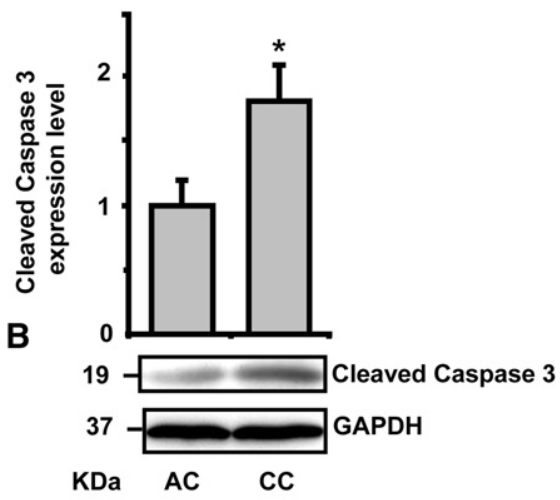

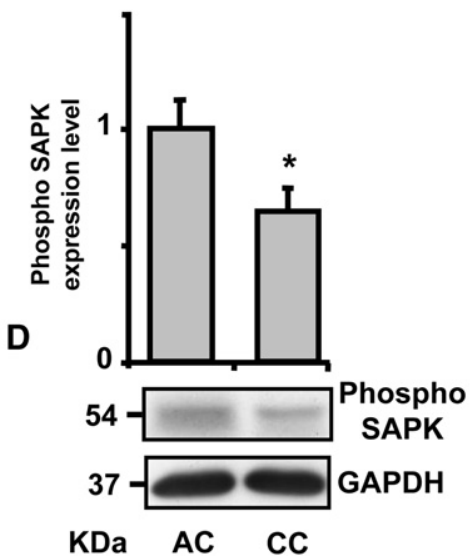

FIGURE E7. Functional validation of hypoxia-inducible factor 1 alpha, cleaved caspase-3, BAX, and phospho-SAPK protein levels in myocardium of acyanotic $(A C)$ and cyanotic $(C C)$ patients. Biopsy specimens were lysed to isolate protein content, and Western blotting analysis was performed, probing for HIF1 $\alpha$ (A), cleaved caspase-3 (B), BAX (C), phospho-SAPK (D) and glyceraldehude-3-phosphate dehydrogenase (GAPDH). HIF1 $\alpha$, cleaved caspase-3, and BAX were significantly upregulated in cyanotic compared with acyanotic biopsy specimens. Phospho-SAPK was significantly downregulated in cyanotic compared with acyanotic biopsy specimens. HIF $1 \alpha$, cleaved caspase-3, BAX, and phospho-SAPK bands were normalized to GAPDH levels. Data are presented as means \pm standard errors of the mean. $* P<.05(\mathrm{n}=6)$. 


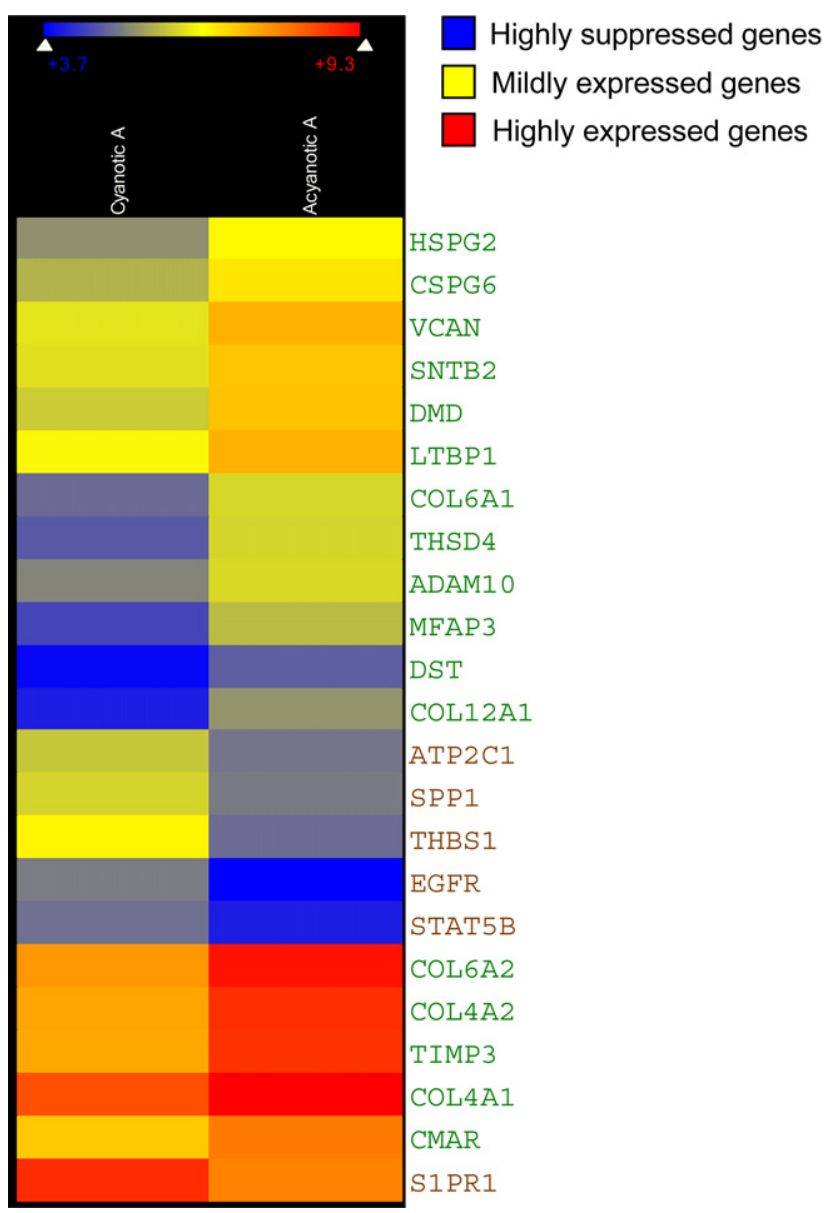

FIGURE E8. Heat Map illustrating the expression levels of the genes implicated in extracellular matrix. Gene symbols in brown represent transcripts that were upregulated in cyanotic patients, whereas gene symbols in green represent genes downregulated by means of cyanosis. Hierarchical clustering has been performed with ArrayStar software. A 3-color scale was used to illustrate expression level differences, with blue indicating low expression values, yellow indicating intermediately expressed genes, and red representing highly expressed genes. 
TABLE E1. Genes exhibiting 1.8-fold or greater expression change in ventricular biopsy specimens of cyanotic versus acyanotic children (upregulated genes)

\begin{tabular}{|c|c|c|c|c|}
\hline Gene title & Symbol & Fold & $P$ value & Gene ID \\
\hline Lysozyme & $L Y Z$ & 5.103 up & .0112 & 4069 \\
\hline Protein phosphatase 1 , catalytic subunit, beta isoform & $P P P 1 C B$ & 3.849 up & .00559 & 5500 \\
\hline Early growth response 1 & EGRl & 3.498 up & .0213 & 1958 \\
\hline RAP2C, member of RAS oncogene family & $R A P 2 C$ & 3.364 up & .0063 & 57826 \\
\hline Thrombospondin 1 & THBS1 & 3.285 up & .0265 & 7057 \\
\hline Nipsnap homolog $3 \mathrm{~A}$ & NIPSNAP3A & 3.055 up & .0229 & 25934 \\
\hline Ubiquitin B & $U B B$ & 3.008 up & .00998 & 7314 \\
\hline $\begin{array}{l}\text { NADH dehydrogenase (ubiquinone) } 1 \text { alpha } \\
\text { subcomplex, } 5,13 \mathrm{kd}\end{array}$ & NDUFA5 & 2.984 up & .0187 & 4698 \\
\hline EF-hand calcium binding domain 2 & $E F C A B 2$ & 2.946 up & .0214 & 84288 \\
\hline Lactamase, beta 2 & $\angle A C T B 2$ & 2.815 up & .0139 & 51110 \\
\hline Hypothetical protein DKFZp564O0523 & DKFZP564O0523 & 2.769 up & .0101 & 84060 \\
\hline Beta-1,3-N-acetylgalactosaminyltransferase 1 & $B 3 G A L N T 1$ & 2.748 up & .0355 & 8706 \\
\hline Actin-binding rho-activating protein & $A B R A$ & 2.711 up & .0112 & 137735 \\
\hline Eukaryotic translation initiation factor $4 \mathrm{E}$ & EIF4E & 2.706 up & .0133 & 1977 \\
\hline KIAA0776 & KIAA0776 & 2.694 up & .0372 & 23376 \\
\hline CDNA FLJ32626 fis, clone SYNOV1000045 & & 2.692 up & .0448 & \\
\hline CDNA clone IMAGE:4820809 & & 2.685 up & .0113 & \\
\hline COBW domain containing 1 & $C B W D 1$ & 2.681 up & .0212 & 150472 \\
\hline Zinc finger E-box binding homeobox 2 & $Z E B 2$ & 2.671 up & .0129 & 9839 \\
\hline Proteasome maturation protein & POMP & 2.639 up & .0107 & 51371 \\
\hline Integral membrane protein $2 \mathrm{~A}$ & ITM2A & 2.631 up & .016 & 9452 \\
\hline Succinate-CoA ligase, GDP-forming, beta subunit & SUCLG2 & 2.629 up & .0443 & 8801 \\
\hline Ubiquitin-specific peptidase 28 & USP28 & 2.612 up & .0124 & 57646 \\
\hline Lysophospholipase I & LYPLA1 & 2.583 up & .0109 & 10434 \\
\hline KIAA0372 & KIAA0372 & 2.579 up & .0139 & 9652 \\
\hline Epidermal growth factor receptor (v-erb-b oncogene) & $E G F R$ & 2.553 up & .0102 & 1956 \\
\hline Family with sequence similarity 76 , member B & $F A M 76 B$ & 2.552 up & .0473 & 143684 \\
\hline FYVE, RhoGEF and PH domain containing 4 & $F G D 4$ & 2.543 up & .0211 & 121512 \\
\hline Hypothetical protein FLJ13611 & FLJ13611 & 2.534 up & .011 & 80006 \\
\hline COX11 homolog, cytochrome c oxidase assembly protein & COX11 & 2.530 up & .00736 & 1353 \\
\hline Hypothetical LOC401397 & LOC401397 & 2.484 up & .0167 & 401397 \\
\hline Kelch-like 20 & KLHL20 & 2.435 up & .0142 & 27252 \\
\hline FCF1 small subunit (SSU) processome component homolog & $F C F 1$ & 2.431 up & .0163 & 93487 \\
\hline Calmodulin 3 (phosphorylase kinase, delta) & $C A L M 3$ & 2.431 up & .0205 & 808 \\
\hline Family with sequence similarity 73 , member A & FAM73A & 2.431 up & .0228 & 374986 \\
\hline CDNA clone IMAGE:5299642 & & 2.407 up & .0432 & \\
\hline Proteasome (prosome, macropain) 26S subunit, ATPase, 2 & PSMC2 & 2.368 up & .0135 & 5701 \\
\hline Tumor necrosis factor (ligand) superfamily, member 10 & TNFSF 10 & 2.363 up & .0456 & 8743 \\
\hline CDNA clone IMAGE:5267328 & & 2.361 up & .016 & \\
\hline Fibroblast growth factor 7 & $F G F 7$ & 2.338 up & .0381 & 2252 \\
\hline EGF-containing fibulin-like extracellular matrix protein 1 & EFEMPl & 2.311 up & .0422 & 2202 \\
\hline Cytochrome P450, family 51, subfamily A, polypeptide 1 & CYP51A1 & 2.276 up & .0113 & 1595 \\
\hline $\begin{array}{l}\text { Protein phosphatase 1B (formerly 2C), magnesium-dependent, } \\
\text { beta isoform }\end{array}$ & $P P M 1 B$ & 2.264 up & .00902 & 5495 \\
\hline Lumican & $L U M$ & 2.260 up & .025 & 4060 \\
\hline Serpin peptidase inhibitor, clade B (ovalbumin), member 9 & SERPINB9 & 2.260 up & .0391 & 5272 \\
\hline Amyotrophic lateral sclerosis 2 (juvenile) & $A L S 2$ & 2.256 up & .0112 & 57679 \\
\hline Rab geranylgeranyltransferase, beta subunit & $R A B G G T B$ & 2.255 up & .00808 & 5876 \\
\hline Ubiquitin-conjugating enzyme E2D 1 (UBC4/5 homolog, yeast) & $U B E 2 D 1$ & 2.243 up & .0281 & 7321 \\
\hline Hypothetical protein LOC386597 & LOC 386597 & 2.233 up & .0107 & 386597 \\
\hline Tubulin, epsilon 1 & TUBE1 & 2.213 up & .0182 & 51175 \\
\hline COMM domain containing 8 & COMMD8 & 2.204 up & .016 & 54951 \\
\hline Erythropoietin receptor & EPOR & 2.190 up & .016 & 2057 \\
\hline
\end{tabular}


TABLE E1. Continued

\begin{tabular}{|c|c|c|c|c|}
\hline Gene title & Symbol & Fold & $P$ value & Gene ID \\
\hline Adaptor-related protein complex 1 , sigma 2 subunit & $A P 1 S 2$ & 2.186 up & .0454 & 8905 \\
\hline Striatin, calmodulin binding protein 3 & STRN3 & 2.186 up & .0243 & 29966 \\
\hline Phosphatase and actin regulator 2 & PHACTR2 & 2.181 up & .0203 & 9749 \\
\hline Zinc-binding alcohol dehydrogenase, domain containing 1 & $\mathrm{ZADH1}$ & 2.162 up & .0266 & 145482 \\
\hline Tetraspanin 12 & TSPAN12 & 2.159 up & .036 & 23554 \\
\hline Transcribed locus & & 2.157 up & .0121 & \\
\hline Ankyrin 1 , erythrocytic & ANK1 & 2.148 up & .0298 & 286 \\
\hline Adenosine kinase & $A D K$ & 2.143 up & .0113 & 132 \\
\hline Chromosome 18 open reading frame 55 & C18orf55 & 2.140 up & .0169 & 29090 \\
\hline Solute carrier family 22 , member 25 & UST6 & 2.130 up & .0242 & 387601 \\
\hline $\begin{array}{l}\text { Glycine amidinotransferase (L-arginine:glycine } \\
\text { amidinotransferase) }\end{array}$ & GATM & 2.130 up & .0343 & 2628 \\
\hline Arginyltransferase 1 & ATE1 & 2.130 up & .0291 & 11101 \\
\hline $\begin{array}{l}\text { Serum deprivation response } \\
\text { (phosphatidylserine-binding protein) }\end{array}$ & $S D P R$ & 2.128 up & .0391 & 8436 \\
\hline Calponin 3 , acidic & CNN3 & 2.125 up & .0407 & 1266 \\
\hline Hypothetical protein LOC285708 & LOC285708 & $\begin{array}{l}2.110 \text { up } \\
2.106 \text { up }\end{array}$ & $\begin{array}{l}.0154 \\
.0368\end{array}$ & 285708 \\
\hline Chromosome 10 open reading frame 110 & C10orf110 & 2.102 up & .0482 & 55853 \\
\hline Stomatin (EPB72)-like 1 & STOML1 & 2.099 up & .011 & 9399 \\
\hline Heterogeneous nuclear ribonucleoprotein $\mathrm{H} 1(\mathrm{H})$ & HNRPHI & 2.092 up & .0254 & 3187 \\
\hline $\begin{array}{l}\text { Solute carrier family } 2 \text { (facilitated glucose transporter), } \\
\text { member } 13\end{array}$ & $S L C 2 A 13$ & 2.092 up & .0237 & 114134 \\
\hline Pallidin homolog (mouse) & $P L D N$ & 2.087 up & .0138 & 26258 \\
\hline Trinucleotide repeat containing $6 \mathrm{~B}$ & $T N R C 6 B$ & 2.079 up & .0357 & 23112 \\
\hline $\begin{array}{l}\text { Ubiquitin-conjugating enzyme E2D } 1 \\
\text { (UBC4/5 homolog, yeast) }\end{array}$ & $U B E 2 D 1$ & 2.075 up & .0342 & 7321 \\
\hline $\begin{array}{l}\text { Nuclear factor of activated T cells, cytoplasmic, } \\
\text { calcineurin-dependent } 2 \text { interacting protein }\end{array}$ & NFATC2IP & 2.075 up & .0136 & 84901 \\
\hline Syntaxin-binding protein 3 & STXBP3 & 2.073 up & .0115 & 6814 \\
\hline $\begin{array}{l}\text { Transcription elongation factor B (SIII), polypeptide } 1 \\
\quad(15 \mathrm{kd} \text {, elongin } \mathrm{C})\end{array}$ & TCEB1 & 2.071 up & .0243 & 6921 \\
\hline EF-hand domain family, member A2 & EFHA2 & 2.064 up & .0142 & 286097 \\
\hline Lyrm7 homolog (mouse) & LYRM7 & 2.052 up & .0481 & 90624 \\
\hline ARP3 actin-related protein 3 homolog (yeast) & ACTR3 & 2.048 up & .0298 & 10096 \\
\hline Short coiled-coil protein & $S C O C$ & 2.047 up & .0213 & 60592 \\
\hline Ribosomal protein L15///similar to ribosomal protein L15 & RPL15 & 2.047 up & .0212 & 728088 \\
\hline Hypothetical LOC441642 & LOC441642 & 2.046 up & .0159 & 441642 \\
\hline CDNA clone IMAGE:4794011 & & 2.043 up & .0237 & \\
\hline Homo sapiens, clone IMAGE:4480721, mRNA & & 2.043 up & .0448 & \\
\hline Chromosome 8 open reading frame 4 & C8orf4 & 2.042 up & .0388 & 56892 \\
\hline Polymerase (RNA) II (DNA directed) polypeptide K, $7.0 \mathrm{kd}$ & $P O L R 2 K$ & 2.042 up & .0176 & 5440 \\
\hline PRO1268 protein & PRO1268 & 2.040 up & .0237 & 29006 \\
\hline Sarcolemma-associated protein & SLMAP & 2.038 up & .0169 & 7871 \\
\hline $\begin{array}{l}\text { Glyceraldehyde-3-phosphate dehydrogenase-like 19///similar } \\
\text { to glyceraldehyde-3-phosphate dehydrogenase (GAPDH) }\end{array}$ & $\begin{array}{l}\text { GAPDHL19/// } \\
\quad \text { LOC732268 }\end{array}$ & 2.036 up & .0153 & $\begin{array}{r}442262 / / / \\
732268\end{array}$ \\
\hline Eukaryotic translation initiation factor $4 \mathrm{E}$ & $E I F 4 E$ & 2.033 up & .0264 & 1977 \\
\hline WD repeat and SOCS box-containing 2 & WSB2 & 2.031 up & .0371 & 55884 \\
\hline CDNA FLJ32691 fis, clone TESTI2000221 & & 2.022 up & .00678 & \\
\hline COMM domain containing 10 & COMMD10 & 2.020 up & .0196 & 51397 \\
\hline Zinc finger protein, $\mathrm{X}$-linked & $Z F X$ & 2.014 up & .0112 & 7543 \\
\hline Ribosomal protein L23a pseudogene 7 & $R P L 23 A P 7$ & 2.011 up & .0106 & 118433 \\
\hline SH3 domain-binding glutamic acid-rich protein like & $S H 3 B G R L$ & 2.004 up & .0214 & 6451 \\
\hline p21 (CDKN1A)-activated kinase 2 & $P A K 2$ & 2.002 up & .0114 & 5062 \\
\hline Copine IV & CPNE4 & 2.000 up & .0172 & 131034 \\
\hline
\end{tabular}


TABLE E1. Continued

\begin{tabular}{|c|c|c|c|c|}
\hline Gene title & Symbol & Fold & $P$ value & Gene ID \\
\hline NLR family, pyrin domain containing 1 & $N L R P 1$ & 1.999 up & .0303 & 22861 \\
\hline X-prolyl aminopeptidase (aminopeptidase P) 3, putative & XPNPEP3 & 1.998 up & .0379 & 63929 \\
\hline Ribosomal protein L37a & RPL37A & 1.997 up & .035 & 6168 \\
\hline Protein tyrosine phosphatase type IVA, member 1 & PTP4A1 & 1.989 up & .0175 & 7803 \\
\hline CDNA FLJ30565 fis, clone BRAWH2005008 & & 1.988 up & .0169 & \\
\hline Basic leucine zipper nuclear factor 1 (JEM-1) & $B L Z F 1$ & 1.987 up & .0405 & 8548 \\
\hline Karyopherin alpha 2 (RAG cohort 1 , importin alpha 1) & KPNA2 & 1.986 up & .0242 & 3838 \\
\hline Transcribed locus & & 1.982 up & .0437 & \\
\hline Insulin-like growth factor binding protein 7 & $I G F B P 7$ & 1.981 up & .0404 & 3490 \\
\hline Centrosomal protein $170 \mathrm{kd}$ & CEP170 & 1.977 up & .0458 & 9859 \\
\hline B-cell chronic lymphocytic leukemia/lymphoma 10 & $B C L 10$ & 1.964 up & .0237 & 8915 \\
\hline Poly(A) binding protein interacting protein 1 & PAIP1 & 1.962 up & .0347 & 10605 \\
\hline Mediterranean fever & $M E F V$ & 1.957 up & .0137 & 4210 \\
\hline Similar to $60 \mathrm{~S}$ ribosomal protein $\mathrm{L} 35$ & LOC643653 & 1.957 up & .0222 & 643653 \\
\hline Annexin A7 & ANXA7 & 1.955 up & .012 & 310 \\
\hline Folliculin & $F L C N$ & 1.952 up & .0255 & 201163 \\
\hline Septin 7 & SEPT7 & 1.948 up & .0483 & 989 \\
\hline TM2 domain containing 1 & $T M 2 D 1$ & 1.945 up & .0157 & 83941 \\
\hline CD8a molecule & $C D 8 A$ & 1.942 up & .0186 & 925 \\
\hline $\begin{array}{l}\text { Secreted phosphoprotein } 1 \text { (osteopontin, bone sialoprotein I, } \\
\text { early T-lymphocyte activation 1) }\end{array}$ & $S P P 1$ & 1.941 up & .0115 & 6696 \\
\hline Selenoprotein P, plasma, 1 & SEPP1 & 1.937 up & .0206 & 6414 \\
\hline Transmembrane protein 123 & TMEM123 & 1.935 up & .011 & 114908 \\
\hline CDNA clone IMAGE:5273964 & & 1.935 up & .0483 & \\
\hline Src kinase-associated phosphoprotein 2 & SKAP2 & 1.934 up & .0406 & 8935 \\
\hline \multirow[t]{2}{*}{ Cyclin-dependent kinase inhibitor 2C (p18, inhibits CDK4) } & $C D K N 2 C$ & 1.933 up & .0125 & 1031 \\
\hline & & 1.927 up & .024 & \\
\hline Transcribed locus & & 1.926 up & .0221 & \\
\hline Spermidine/spermine N1-acetyltransferase 1 & SAT1 & 1.925 up & .0162 & 6303 \\
\hline THAP domain containing 5 & THAP5 & 1.924 up & .0113 & 168451 \\
\hline Actin-like 6A & ACTL6A & 1.923 up & .0182 & 86 \\
\hline SMT3 suppressor of mif two 3 homolog 1 (S cerevisiae) & SUMO1 & 1.922 up & .00972 & 7341 \\
\hline MAD2 mitotic arrest deficient-like 1 (yeast) & $M A D 2 L 1$ & 1.922 up & .0114 & 4085 \\
\hline MANSC domain containing 1 & MANSC1 & 1.921 up & .0232 & 54682 \\
\hline $\begin{array}{l}\text { Endothelial differentiation, sphingolipid } \\
\text { G protein-coupled receptor, } 1\end{array}$ & $E D G 1$ & 1.915 up & .0242 & 1901 \\
\hline Wingless-type MMTV integration site family, member 6 & WNT6 & 1.914 up & .0387 & 7475 \\
\hline Carboxypeptidase E & $C P E$ & 1.914 up & .0236 & 1363 \\
\hline Transcribed locus & & 1.909 up & .0315 & \\
\hline Interleukin 33 & IL33 & 1.901 up & .0456 & 90865 \\
\hline OMA1 homolog, zinc metallopeptidase ( $S$ cerevisiae) & OMAl & 1.899 up & .0263 & 115209 \\
\hline Calreticulin & $C A L R$ & 1.898 up & .0443 & 811 \\
\hline Clone 114 tumor rejection antigen & & 1.895 up & .0405 & \\
\hline \multirow{2}{*}{$\begin{array}{l}\text { Solute carrier family } 12 \\
\text { (sodium/potassium/chloride transporters), member } 2\end{array}$} & $S L C 12 A 2$ & 1.893 up & .0158 & 6558 \\
\hline & & 1.893 up & .0217 & \\
\hline EF-hand domain family, member A1 & EFHAl & 1.892 up & .0243 & 221154 \\
\hline Ribosomal protein L38 & RPL38 & 1.890 up & .0253 & 6169 \\
\hline Homo sapiens, clone IMAGE:5440917, mRNA & & 1.889 up & .0374 & \\
\hline Yip1 domain family, member 4 & YIPF4 & 1.887 up & .0146 & 84272 \\
\hline $\begin{array}{l}\text { Guanine nucleotide binding protein (G protein), } \\
\text { gamma 10///hypothetical protein LOC552891 }\end{array}$ & $\begin{array}{l}\text { GNG10/// } \\
\quad \text { LOC552891 }\end{array}$ & 1.884 up & .0224 & $\begin{array}{c}2790 / / / \\
552891\end{array}$ \\
\hline Peroxisomal biogenesis factor 7 & PEX7 & 1.881 up & .0135 & 5191 \\
\hline Signal transducer and activator of transcription 5B & STAT5B & 1.881 up & .0195 & 6777 \\
\hline $3^{\prime}\left(2^{\prime}\right), 5^{\prime}$-Bisphosphate nucleotidase 1 & $B P N T 1$ & 1.876 up & .0281 & 10380 \\
\hline
\end{tabular}


TABLE E1. Continued

\begin{tabular}{|c|c|c|c|c|}
\hline Gene title & Symbol & Fold & $P$ value & Gene ID \\
\hline $\begin{array}{l}\text { Inhibitor of DNA binding 2, dominant negative } \\
\text { helix-loop-helix protein///inhibitor of DNA binding } \\
\text { 2B, dominant negative helix-loop-helix protein }\end{array}$ & $I D 2 / / / I D 2 B$ & 1.875 up & .0448 & $3398 / / / 84099$ \\
\hline Eukaryotic translation initiation factor $1 \mathrm{~A}, \mathrm{X}$-linked & EIF1AX & 1.866 up & .0317 & 1964 \\
\hline OTU domain containing $6 \mathrm{~B}$ & OTUD6B & 1.865 up & .0325 & 51633 \\
\hline RAB12, member RAS oncogene family & $R A B 12$ & 1.864 up & .024 & 201475 \\
\hline Late cornified envelope $1 \mathrm{E}$ & LCEIE & 1.862 up & .00469 & 353135 \\
\hline RNA binding motif (RNP1, RRM) protein 3 & $R B M 3$ & 1.862 up & .0125 & 5935 \\
\hline Thiopurine S-methyltransferase & TPMT & 1.858 up & .0232 & 7172 \\
\hline Mitochondrial ribosomal protein L50 & MRPL50 & 1.856 up & .0389 & 54534 \\
\hline Hydroxysteroid dehydrogenase like 2 & $H S D L 2$ & 1.853 up & .0352 & 84263 \\
\hline CDNA clone IMAGE:4830861 & & 1.849 up & .0181 & \\
\hline $\begin{array}{l}\text { Methylenetetrahydrofolate dehydrogenase } \\
\left(\text { NADP }^{+} \text {dependent) } 2-\text { like }\right.\end{array}$ & MTHFD2L & 1.847 up & .0293 & 441024 \\
\hline Jagged 1 (Alagille syndrome) & $J A G 1$ & $\begin{array}{l}1.847 \text { up } \\
1.847 \text { up }\end{array}$ & $\begin{array}{l}.0319 \\
.0111\end{array}$ & 182 \\
\hline Myozenin 2 & MYOZ2 & 1.843 up & .032 & 51778 \\
\hline Family with sequence similarity 115 , member A & FAM115A & 1.842 up & 0368 & 9747 \\
\hline $\begin{array}{l}\text { Cysteine and histidine-rich domain } \\
\text { (CHORD)-containing } 1\end{array}$ & CHORDC1 & 1.841 up & .0109 & 26973 \\
\hline ATPase, $\mathrm{Ca}^{++}$transporting, type $2 \mathrm{C}$, member 1 & $A T P 2 C 1$ & 1.841 up & .0435 & 27032 \\
\hline Copine IV & CPNE4 & 1.841 up & .0149 & 131034 \\
\hline NLR family, pyrin domain containing 1 & $N L R P 1$ & 1.834 up & .0241 & 22861 \\
\hline Basic transcription factor 3 & $B T F 3$ & 1.834 up & .0104 & 689 \\
\hline Golgi transport 1 homolog B (S cerevisiae) & GOLT1B & 1.833 up & .0312 & 51026 \\
\hline Transcribed locus & & 1.832 up & .0171 & \\
\hline Hypothetical protein FLJ22222 & FLJ22222 & 1.829 up & .0115 & 79701 \\
\hline Dihydropyrimidine dehydrogenase & $D P Y D$ & 1.826 up & .0395 & 1806 \\
\hline Chromosome 5 open reading frame 33 & C5orf33 & 1.825 up & .0109 & 133686 \\
\hline $\begin{array}{l}\text { Epidermal growth factor receptor (erythroblastic } \\
\text { leukemia viral (v-erb-b) oncogene homolog, avian) }\end{array}$ & $E G F R$ & 1.824 up & .0152 & 1956 \\
\hline Jerky homolog-like (mouse) & $J R K L$ & 1.824 up & .0387 & 8690 \\
\hline Sphingomyelin synthase 1 & SGMS1 & 1.824 up & 0109 & 259230 \\
\hline Zinc finger protein 654 & ZNF654 & 1.823 up & .0367 & 55279 \\
\hline $\begin{array}{l}\text { Transcribed locus (serine/threonine kinase 17B) } \\
\text { (apoptosis-inducing) }\end{array}$ & STK17B & 1.819 up & .0236 & \\
\hline Gap junction protein, beta $4,30.3 \mathrm{kd}$ & GJB4 & 1.814 up & .032 & 127534 \\
\hline Sp3 transcription factor & $S P 3$ & 1.813 up & .0124 & 6670 \\
\hline Leucine-rich repeat containing 25 & $L R R C 25$ & 1.813 up & .028 & 126364 \\
\hline Transmembrane and tetratricopeptide repeat containing 3 & TMTC3 & 1.813 up & .0209 & 160418 \\
\hline Nucleosome assembly protein 1 -like 1 & NAPlL1 & 1.812 up & .0266 & 4673 \\
\hline Fibrinogen-like 2 & $F G L 2$ & 1.812 up & .0191 & 10875 \\
\hline Zinc finger protein 552 & ZNF552 & 1.808 up & .0125 & 79818 \\
\hline Hypothetical gene supported by AK023501 & FLJ13439 & 1.808 up & .0206 & 399876 \\
\hline Full-length insert cDNA clone ZD82B02 & & 1.807 up & .0197 & \\
\hline Mesenchymal stem cell protein DSC96 & & 1.805 up & .034 & \\
\hline $\begin{array}{l}\text { Apolipoprotein B mRNA editing enzyme, catalytic } \\
\text { polypeptide-like } 3 \mathrm{G}\end{array}$ & $A P O B E C 3 G$ & 1.803 up & .0176 & 60489 \\
\hline $\begin{array}{l}\text { Eukaryotic translation initiation factor } 1 \mathrm{~A}, \\
\text { X-linked///eukaryotic translation initiation } \\
\text { factor 1A pseudogene } 1\end{array}$ & EIF1AP1///EIF1AX & 1.803 up & .0298 & $1964 / / / 280661$ \\
\hline GULP, engulfment adaptor PTB domain containing 1 & GULP1 & $1.801 \mathrm{up}$ & .0437 & 51454 \\
\hline
\end{tabular}


TABLE E2. Genes exhibiting 1.8-fold or greater expression change in ventricular biopsy specimens of cyanotic versus acyanotic children (downregulated genes)

\begin{tabular}{|c|c|c|c|c|}
\hline Gene title & Symbol & Fold & $P$ value & Gene ID \\
\hline $\begin{array}{l}\text { Oxoglutarate (alpha-ketoglutarate) } \\
\text { dehydrogenase (lipoamide) }\end{array}$ & $O G D H$ & 6.227 down & .0218 & 4967 \\
\hline Nebulin-related anchoring protein & NRAP & 5.878 down & .0154 & 4892 \\
\hline Plakophilin 2 & $P K P 2$ & 5.058 down & .0124 & 5318 \\
\hline Mitofusin 2 & $M F N 2$ & 4.453 down & .0216 & 9927 \\
\hline Glucosamine (N-acetyl)-6-sulfatase & GNS & 4.439 down & .0136 & 2799 \\
\hline AHNAK nucleoprotein & AHNAK & 4.417 down & .011 & 79026 \\
\hline $\begin{array}{l}\text { Solute carrier family } 8 \text { (sodium/calcium } \\
\text { exchanger), member } 1\end{array}$ & $S L C 8 A 1$ & 4.284 down & .00929 & 6546 \\
\hline Coatomer protein complex, subunit alpha & COPA & 4.221 down & .0222 & 1314 \\
\hline Cardiomyopathy-associated 5 & CMYA5 & 4.185 down & .0118 & 202333 \\
\hline Phosphodiesterase 4D-interacting protein (myomegalin) & PDE4DIP & 3.875 down & .0114 & 9659 \\
\hline Nuclear mitotic apparatus protein 1 & NUMA1 & 3.768 down & .0116 & 4926 \\
\hline SET domain containing 5 & SETD5 & 3.652 down & .0124 & 55209 \\
\hline Forkhead box $\mathrm{O} 3$ & FOXO3 & 3.606 down & .0271 & 2309 \\
\hline Solute carrier family 39 (zinc transporter), member 14 & SLC39A14 & 3.589 down & .0199 & 23516 \\
\hline Plectin 1, intermediate filament binding protein $500 \mathrm{kd}$ & PLEC1 & 3.542 down & .0228 & 5339 \\
\hline Zinc finger protein $36, \mathrm{C} 3 \mathrm{H}$ type-like 2 & ZFP36L2 & 3.495 down & .0347 & 678 \\
\hline Homeodomain interacting protein kinase 3 & HIPK3 & 3.485 down & .0121 & 10114 \\
\hline Chromosome 19 open reading frame 6 & C19orf6 & 3.457 down & .0113 & 91304 \\
\hline Filamin binding LIM protein 1 & FBLIM1 & 3.429 down & .0314 & 54751 \\
\hline $\begin{array}{l}\text { Interleukin } 6 \text { signal transducer (gp130, } \\
\text { oncostatin M receptor) }\end{array}$ & IL6ST & 3.397 down & .0114 & 3572 \\
\hline YTH domain family, member 3 & $Y T H D F 3$ & 3.396 down & .0146 & 253943 \\
\hline DEAD (Asp-Glu-Ala-Asp) box polypeptide 42 & $D D X 42$ & 3.385 down & .0124 & 11325 \\
\hline AF4/FMR2 family, member 4 & $A F F 4$ & 3.372 down & .0136 & 27125 \\
\hline DEAH (Asp-Glu-Ala-His) box polypeptide 9 & DHX9 & 3.350 down & .011 & 1660 \\
\hline WD repeat domain 68 & WDR68 & 3.246 down & .0131 & 10238 \\
\hline ATPase type $13 \mathrm{~A} 3$ & ATP13A3 & 3.204 down & .00672 & 79572 \\
\hline Sec61 alpha 1 subunit ( $S$ cerevisiae) & SEC61A1 & 3.183 down & .0175 & 29927 \\
\hline Chaperone, $\mathrm{ABC} 1$ activity of bc 1 complex homolog & $C A B C 1$ & 3.182 down & .0219 & 56997 \\
\hline Signal-induced proliferation-associated 1 like 2 & SIPAIL2 & 3.164 down & .0183 & 57568 \\
\hline Gelsolin (amyloidosis, Finnish type) & $G S N$ & 3.155 down & .0125 & 2934 \\
\hline A kinase (PRKA) anchor protein 6 & AKAP6 & 3.123 down & .00579 & 9472 \\
\hline Peroxisome proliferator-activated receptor alpha & PPARA & 3.107 down & .03 & 5465 \\
\hline PDZ and LIM domain 5 & PDLIM5 & 3.101 down & .0125 & 10611 \\
\hline Tetratricopeptide repeat domain 3 & TTC3 & 3.088 down & .0109 & 7267 \\
\hline Sp1 transcription factor & $S P 1$ & 3.080 down & .0146 & 6667 \\
\hline Trafficking protein, kinesin binding 1 & TRAK1 & 3.074 down & .0224 & 22906 \\
\hline Inositol polyphosphate-5-phosphatase, $40 \mathrm{kd}$ & $I N P P 5 A$ & 3.072 down & .0145 & 3632 \\
\hline Phosphodiesterase 3A, cGMP-inhibited & $P D E 3 A$ & 3.069 down & .00601 & 5139 \\
\hline Suppressor of Ty 16 homolog (S cerevisiae) & SUPT16H & 3.057 down & .0187 & 11198 \\
\hline Nucleoporin $62 \mathrm{kd}$ & NUP62 & 3.054 down & .0161 & 23636 \\
\hline Proteasome (prosome, macropain) activator subunit 4 & PSME4 & 3.047 down & .0113 & 23198 \\
\hline FYVE, RhoGEF and PH domain containing 4 & FGD4 & 3.043 down & .00671 & 121512 \\
\hline ELKS/RAB6-interacting/CAST family member 1 & ERC1 & 3.033 down & .0219 & 23085 \\
\hline PRP6 pre-mRNA processing factor 6 homolog & PRPF6 & 3.029 down & .0125 & 24148 \\
\hline Collagen, type VI, alpha 1 & COL6Al & 3.000 down & .00664 & 1291 \\
\hline Myotubularin related protein 1 & MTMRI & 2.983 down & .00996 & 8776 \\
\hline CDNA FLJ38472 fis, clone FEBRA2022148 & & 2.981 down & .0437 & \\
\hline Transformation/transcription domain-associated protein & TRRAP & 2.973 down & .0136 & 8295 \\
\hline Ubiquitination factor E4B (UFD2 homolog, yeast) & $U B E 4 B$ & 2.970 down & .0116 & 10277 \\
\hline Myeloid cell leukemia sequence 1 (BCL2-related) & $M C L 1$ & 2.967 down & .0218 & 4170 \\
\hline ATPase, $\mathrm{Ca}^{++}$transporting, plasma membrane 4 & $A T P 2 B 4$ & 2.957 down & .0121 & 493 \\
\hline
\end{tabular}


TABLE E2. Continued

\begin{tabular}{|c|c|c|c|c|}
\hline Gene title & Symbol & Fold & $P$ value & Gene ID \\
\hline Filamin A interacting protein 1 & FILIP1 & 2.950 down & .0066 & 27145 \\
\hline Ribosomal protein S23 & RPS23 & 2.945 down & .0156 & 6228 \\
\hline Carboxypeptidase D & $C P D$ & 2.937 down & .0137 & 1362 \\
\hline F-box and WD repeat domain containing 11 & $F B X W 11$ & 2.925 down & .0112 & 23291 \\
\hline LAG1 homolog, ceramide synthase 6 & LASS6 & 2.914 down & .0366 & 253782 \\
\hline $\begin{array}{l}\text { SWI/SNF related, matrix associated, actin dependent } \\
\text { regulator of chromatin, subfamily a, member } 2\end{array}$ & SMARCA2 & 2.905 down & .0111 & 6595 \\
\hline Sorbin and SH3 domain containing 1 & SORBSI & 2.894 down & .0176 & 10580 \\
\hline Guanine nucleotide binding protein ( $\mathrm{G}$ protein), alpha 13 & GNA13 & 2.865 down & .0241 & 10672 \\
\hline SCY1-like 2 ( $S$ cerevisiae) & $S C Y L 2$ & 2.852 down & .0119 & 55681 \\
\hline Fas (TNFRSF6) associated factor 1 & $F A F 1$ & 2.819 down & .0139 & 11124 \\
\hline Ezrin & $E Z R$ & 2.818 down & .0295 & 7430 \\
\hline Zinc finger protein 672 & ZNF672 & 2.814 down & .0144 & 79894 \\
\hline GATA binding protein 4 & GATA4 & 2.805 down & .0212 & 2626 \\
\hline Phosphodiesterase 1C, calmodulin-dependent $70 \mathrm{kd}$ & PDEIC & 2.803 down & .0109 & 5137 \\
\hline Fibroblast growth factor receptor 1 & $F G F R 1$ & 2.800 down & .0132 & 2260 \\
\hline Muscleblind-like 2 (Drosophila) & $M B N L 2$ & 2.780 down & .0244 & 10150 \\
\hline Ubiquitin protein ligase E3 component n-recognin 1 & $U B R 1$ & 2.771 down & .0253 & 197131 \\
\hline Sodium channel, voltage-gated, type VII, alpha & $S C N 7 A$ & 2.769 down & .0113 & 6332 \\
\hline Collagen, type VI, alpha 2 & COL6A2 & 2.742 down & .0112 & 1292 \\
\hline Myelin basic protein & $M B P$ & 2.742 down & .0103 & 4155 \\
\hline Eukaryotic translation initiation factor 4 gamma, 1 & $E I F 4 G 1$ & 2.740 down & .0125 & 1981 \\
\hline Exportin 7 & XPO7 & 2.736 down & .0112 & 23039 \\
\hline Endothelial PAS domain protein 1 & EPAS1 & 2.725 down & .0232 & 2034 \\
\hline MutS homolog 6 (E coli) & MSH6 & 2.724 down & .0129 & 2956 \\
\hline Transforming growth factor, beta receptor II $(70 / 80 \mathrm{kd})$ & $T G F B R 2$ & 2.715 down & .0124 & 7048 \\
\hline Gamma-aminobutyric acid (GABA) A receptor, beta 1 & GABRB1 & 2.710 down & .0311 & 2560 \\
\hline Pleckstrin homology-like domain, family B, member 2 & PHLDB2 & 2.706 down & .0174 & 90102 \\
\hline Catenin (cadherin-associated protein), alpha 1, $102 \mathrm{kd}$ & CTNNAl & 2.703 down & .0228 & 1495 \\
\hline Carboxyl ester lipase (bile salt-stimulated lipase) & $C E L$ & 2.700 down & .0449 & 1056 \\
\hline Prune homolog & PRUNE & 2.678 down & .0233 & 58497 \\
\hline BCL2-like 1 & $B C L 2 L 1$ & 2.674 down & .0329 & 598 \\
\hline $\begin{array}{l}\text { Solute carrier family } 16, \text { member } 1 \text { (monocarboxylic } \\
\text { acid transporter 1) }\end{array}$ & SLC16A1 & 2.672 down & .0128 & 6566 \\
\hline $\begin{array}{l}\text { CDNA FLJ38048 fis, clone CTONG2014264///CDNA } \\
\text { FLJ39067 fis, clone NT2RP7014910 }\end{array}$ & & 2.668 down & .0154 & \\
\hline ADP-ribosylation factor guanine nucleotide-exchange factor 2 & $A R F G E F 2$ & 2.654 down & .0168 & 10564 \\
\hline Chromosome 9 open reading frame 5 & C9orf5 & 2.650 down & .01 & 23731 \\
\hline Zinc finger, MYND domain containing 11 & ZMYND11 & 2.635 down & .011 & 10771 \\
\hline Ras homolog gene family, member B & $R H O B$ & 2.634 down & .0488 & 388 \\
\hline Kringle containing transmembrane protein 1 & KREMEN1 & 2.620 down & .0448 & 83999 \\
\hline F-box protein 38 & FBXO38 & 2.617 down & .0125 & 81545 \\
\hline Secretory carrier membrane protein 1 & $S C A M P 1$ & 2.616 down & .011 & 9522 \\
\hline Putative homeodomain transcription factor 2 & PHTF2 & 2.605 down & .0178 & 57157 \\
\hline Spastic paraplegia 7 & SPG7 & 2.598 down & .0451 & 6687 \\
\hline $\begin{array}{l}\text { Membrane protein, palmitoylated } 5 \text { (MAGUK p55 } \\
\text { subfamily member 5) }\end{array}$ & MPP5 & 2.595 down & .0103 & 64398 \\
\hline BCL2-associated transcription factor 1 & $B C L A F 1$ & 2.585 down & .0138 & 9774 \\
\hline Nuclear receptor coactivator 2 & NCOA2 & 2.580 down & .0116 & 10499 \\
\hline Myomesin family, member 3 & МYOMЗ & 2.579 down & .0346 & 127294 \\
\hline Forkhead box N3 & FOXN3 & 2.573 down & .0118 & 1112 \\
\hline Blood vessel epicardial substance & BVES & 2.570 down & .0295 & 11149 \\
\hline $\begin{array}{l}\text { Family with sequence similarity } 62 \text { (C2 domain containing) } \\
\text { member B }\end{array}$ & $F A M 62 B$ & 2.569 down & .0134 & 57488 \\
\hline
\end{tabular}


TABLE E2. Continued

\begin{tabular}{|c|c|c|c|c|}
\hline Gene title & Symbol & Fold & $P$ value & Gene ID \\
\hline $\begin{array}{l}\text { Procollagen-proline, 2-oxoglutarate 4-dioxygenase } \\
\text { (proline 4-hydroxylase), beta polypeptide }\end{array}$ & $P 4 H B$ & 2.564 down & .0384 & 5034 \\
\hline Ubiquitin-specific peptidase 2 & USP2 & 2.544 down & .00576 & 9099 \\
\hline Zinc finger, FYVE domain containing 1 & ZFYVE1 & 2.540 down & .0149 & 53349 \\
\hline General transcription factor II, i & GTF2I & 2.539 down & .0135 & 2969 \\
\hline Son of sevenless homolog 2 & SOS2 & 2.539 down & .0211 & 6655 \\
\hline Thrombospondin, type I, domain containing 4 & THSD4 & 2.536 down & .0177 & 79875 \\
\hline Jumonji domain containing $1 \mathrm{C}$ & $J M J D 1 C$ & 2.533 down & .0098 & 221037 \\
\hline Ring finger protein 38 & RNF38 & 2.532 down & .00664 & 152006 \\
\hline Muscleblind-like & $M B N L 1$ & 2.517 down & .0418 & 4154 \\
\hline Coiled-coil domain containing 93 & $C C D C 93$ & 2.515 down & .0102 & 54520 \\
\hline Cleft lip and palate associated transmembrane protein 1 & CLPTM1 & 2.505 down & .0301 & 1209 \\
\hline HECT domain containing 1 & HECTD1 & 2.502 down & .0133 & 25831 \\
\hline Transmembrane protein 168 & TMEM168 & 2.500 down & .00924 & 64418 \\
\hline ST6 beta-galactosamide alpha-2,6-sialyltranferase 1 & ST6GAL1 & 2.495 down & .0306 & 6480 \\
\hline Glutamate-ammonia ligase (glutamine synthetase) & $G L U L$ & 2.493 down & .0239 & 2752 \\
\hline WD repeat domain 1 & $W D R 1$ & 2.490 down & .0212 & 9948 \\
\hline UBX domain containing 7 & $U B X D 7$ & 2.483 down & .0233 & 26043 \\
\hline Dihydrolipoamide branched chain transacylase E2 & $D B T$ & 2.482 down & .0161 & 1629 \\
\hline Zinc finger, BED-type containing 1 & ZBED1 & 2.478 down & .0168 & 9189 \\
\hline Solute carrier family 29 (nucleoside transporters), member 1 & SLC29A1 & 2.476 down & .0163 & 2030 \\
\hline Mitogen-activated protein kinase 14 & MAPK14 & 2.472 down & .0205 & 1432 \\
\hline GRB2-associated binding protein 1 & $G A B 1$ & 2.465 down & .00951 & 2549 \\
\hline Coiled-coil domain containing 22 & $C C D C 22$ & 2.461 down & .0137 & 28952 \\
\hline Latent transforming growth factor beta binding protein 3 & $L T B P 3$ & 2.459 down & .0169 & 4054 \\
\hline Replication initiator 1 & REPIN1 & 2.455 down & .0256 & 29803 \\
\hline Utrophin & $U T R N$ & 2.452 down & .0111 & 7402 \\
\hline Signal recognition particle receptor ("docking protein") & $S R P R$ & 2.451 down & .0181 & 6734 \\
\hline Forkhead box J3 & FOXJ3 & 2.450 down & .0142 & 22887 \\
\hline Collagen, type XII, alpha 1 & COL12A1 & 2.446 down & .0109 & 1303 \\
\hline $\begin{array}{l}\text { TIMP metallopeptidase inhibitor } 3 \text { (Sorsby fundus } \\
\text { dystrophy, pseudoinflammatory) }\end{array}$ & TIMP3 & 2.445 down & .0338 & 7078 \\
\hline Sperm associated antigen 9 & $S P A G 9$ & 2.445 down & .0109 & 9043 \\
\hline Zinc finger protein 395 & ZNF395 & 2.441 down & .0264 & 55893 \\
\hline A kinase (PRKA) anchor protein 1 & $A K A P 1$ & 2.437 down & .0226 & 8165 \\
\hline Activating transcription factor 2 & $A T F 2$ & 2.434 down & .0145 & 1386 \\
\hline Collagen, type IV, alpha 2 & COL4A2 & 2.431 down & .0277 & 1284 \\
\hline Myelin basic protein & $M B P$ & 2.427 down & .00494 & 4155 \\
\hline Golgi associated PDZ and coiled-coil motif containing & GOPC & 2.424 down & .00952 & 57120 \\
\hline Microfibrillar-associated protein 3 & MFAP3 & 2.423 down & .0171 & 4238 \\
\hline UBX domain containing 2 & $U B X D 2$ & 2.420 down & .0136 & 23190 \\
\hline Heparan sulfate proteoglycan 2 & $H S P G 2$ & 2.415 down & .0109 & 3339 \\
\hline Desmoglein 2 & $D S G 2$ & 2.411 down & .0203 & 1829 \\
\hline Exocyst complex component 4 & EXOC4 & 2.410 down & .019 & 60412 \\
\hline Chloride intracellular channel 4 & CLIC4 & 2.410 down & .0207 & 25932 \\
\hline RAN binding protein 2 & $R A N B P 2$ & 2.405 down & .0116 & 5903 \\
\hline Ring finger and $\mathrm{CCCH}$-type zinc finger domains 2 & $\mathrm{RC} 3 \mathrm{H} 2$ & 2.405 down & .0119 & 54542 \\
\hline $\begin{array}{l}\text { ATP-binding cassette, sub-family C (CFTR/MRP), } \\
\text { member } 9\end{array}$ & $A B C C 9$ & 2.402 down & .0066 & 10060 \\
\hline LSM14B, SCD6 homolog B (S cerevisiae) & $L S M 14 B$ & 2.396 down & .0118 & 149986 \\
\hline Synaptopodin 2 & SYNPO2 & 2.395 down & .0246 & 171024 \\
\hline Tripeptidyl peptidase I & $T P P 1$ & 2.391 down & .0215 & 1200 \\
\hline $\begin{array}{l}\text { Sema domain, transmembrane domain (TM), and cytoplasmic } \\
\text { domain, (semaphorin) 6D }\end{array}$ & SEMA6D & 2.386 down & .0442 & 80031 \\
\hline Discs, large homolog 1 (Drosophila) & $D L G 1$ & 2.382 down & .0197 & 1739 \\
\hline
\end{tabular}


TABLE E2. Continued

\begin{tabular}{|c|c|c|c|c|}
\hline Gene title & Symbol & Fold & $P$ value & Gene ID \\
\hline Obscurin-like 1 & OBSL1 & 2.381 down & .0441 & 23363 \\
\hline Ubiquitination factor E4B (UFD2 homolog, yeast) & $U B E 4 B$ & 2.377 down & .0108 & 10277 \\
\hline LIM domain containing preferred translocation partner in lipoma & $L P P$ & 2.372 down & .0134 & 4026 \\
\hline Plakophilin 4 & PKP4 & 2.366 down & .00687 & 8502 \\
\hline $\begin{array}{l}\text { Dual specificity phosphatase } 3 \text { (vaccinia virus phosphatase } \\
\text { VH1-related) }\end{array}$ & DUSP3 & 2.361 down & .0233 & 1845 \\
\hline Phosphatase and actin regulator 2 & PHACTR2 & 2.361 down & .0158 & 9749 \\
\hline DEAD (Asp-Glu-Ala-Asp) box polypeptide 3, X-linked & $D D X 3 X$ & 2.357 down & .0208 & 1654 \\
\hline $\begin{array}{l}\text { Protein tyrosine phosphatase, nonreceptor type } 11 \text { (Noonan } \\
\text { syndrome 1) }\end{array}$ & PTPN11 & 2.351 down & .0112 & 5781 \\
\hline Chromosome 6 open reading frame 106 & C6orf106 & 2.348 down & .012 & 64771 \\
\hline Rho GTPase activating protein 5 & ARHGAP5 & 2.348 down & .0103 & 394 \\
\hline $\begin{array}{l}\text { Runt-related transcription factor } 1 \text {; translocated to, } 1 \\
\quad \text { (cyclin D-related) }\end{array}$ & $R U N X 1 T 1$ & 2.348 down & .0119 & 862 \\
\hline Phosphoinositide-3-kinase, class 2, alpha polypeptide & $P I K 3 C 2 A$ & 2.347 down & .0169 & 5286 \\
\hline Phospholipase D1, phosphatidylcholine-specific & $P L D 1$ & 2.347 down & .0256 & 5337 \\
\hline Dystrophin (muscular dystrophy, Duchenne and Becker types) & $D M D$ & 2.344 down & .00618 & 1756 \\
\hline Ankyrin 2, neuronal & $A N K 2$ & 2.343 down & .00798 & 287 \\
\hline Janus kinase 1 (a protein tyrosine kinase) & $J A K 1$ & 2.340 down & .0227 & 3716 \\
\hline Lamin $\mathrm{A} / \mathrm{C}$ & $L M N A$ & 2.335 down & .0134 & 4000 \\
\hline Bromodomain containing 4 & BRD4 & 2.334 down & .039 & 23476 \\
\hline Ubiquitin specific peptidase 42 & USP42 & 2.321 down & .0166 & 84132 \\
\hline Methyl CpG binding protein 2 (Rett syndrome) & $M E C P 2$ & 2.320 down & .0479 & 4204 \\
\hline $\begin{array}{l}\text { Transglutaminase } 2 \text { (C polypeptide, protein-glutamine-gamma- } \\
\text { glutamyltransferase) }\end{array}$ & $T G M 2$ & 2.319 down & .0206 & 7052 \\
\hline Ankylosis, progressive homolog (mouse) & ANKH & 2.312 down & .0205 & 56172 \\
\hline Muskelin 1, intracellular mediator containing kelch motifs & $M K L N 1$ & 2.311 down & .0249 & 4289 \\
\hline Lysosomal-associated membrane protein 1 & $L A M P 1$ & 2.311 down & .0274 & 3916 \\
\hline CUG triplet repeat, RNA binding protein 1 & $C U G B P 1$ & 2.309 down & .0112 & 10658 \\
\hline Secretory carrier membrane protein 1 & $S C A M P 1$ & 2.308 down & .0113 & 9522 \\
\hline WD repeat domain 68 & WDR68 & 2.307 down & .0172 & 10238 \\
\hline Ribosomal protein S6 kinase, $90 \mathrm{kd}$, polypeptide 2 & RPS6KA2 & 2.304 down & .0354 & 6196 \\
\hline Junctional adhesion molecule 3 & $J A M 3$ & 2.303 down & .0158 & 83700 \\
\hline Bromodomain containing 2 & $B R D 2$ & 2.294 down & .022 & 6046 \\
\hline Phosphatidylinositol 4-kinase, catalytic, beta & $P I 4 K B$ & 2.292 down & .0128 & 5298 \\
\hline Jun D proto-oncogene & $J U N D$ & 2.289 down & .0242 & 3727 \\
\hline $\begin{array}{l}\text { Microtubule associated serine/threonine kinase } \\
\text { family member } 4\end{array}$ & MAST4 & 2.285 down & .0448 & 375449 \\
\hline Utrophin & $U T R N$ & 2.284 down & .011 & 7402 \\
\hline Chromosome 11 open reading frame 30 & C11orf30 & 2.284 down & .0433 & 56946 \\
\hline RAB6A, member RAS oncogene family & $R A B 6 A$ & 2.283 down & .0134 & 5870 \\
\hline Chromosome 4 open reading frame 18 & C4orf18 & 2.283 down & .0142 & 51313 \\
\hline $\begin{array}{l}\text { Protein tyrosine phosphatase, non-receptor type } 11 \\
\text { (Noonan syndrome 1) }\end{array}$ & PTPN11 & 2.283 down & .00661 & 5781 \\
\hline Upstream binding transcription factor, RNA polymerase I & $U B T F$ & 2.281 down & .0101 & 7343 \\
\hline Collagen, type VI, alpha 1 & COL6A1 & 2.280 down & .0169 & 1291 \\
\hline Calcium channel, voltage-dependent, beta 2 subunit & $C A C N B 2$ & 2.280 down & .0449 & 783 \\
\hline Corin, serine peptidase & CORIN & 2.277 down & .0284 & 10699 \\
\hline Spire homolog 1 (Drosophila) & SPIRE1 & 2.276 down & .0311 & 56907 \\
\hline Collagen, type VI, alpha 1 & COL6A1 & 2.273 down & .00933 & 1291 \\
\hline Angiopoietin-like 2 & ANGPTL2 & 2.272 down & .0125 & 23452 \\
\hline Sortilin 1 & SORT1 & 2.271 down & .0214 & 6272 \\
\hline Vacuolar protein sorting 35 homolog (S cerevisiae) & VPS35 & 2.269 down & .0219 & 55737 \\
\hline ADAM metallopeptidase domain 9 (meltrin gamma) & ADAM9 & 2.269 down & .016 & 8754 \\
\hline Palladin, cytoskeletal associated protein & $P A L L D$ & 2.266 down & .0127 & 23022 \\
\hline
\end{tabular}




\section{$\frac{\text { Gene title }}{\text { Tumor necrosis factor receptor superfamily, member } 19}$}

Zinc finger protein, X-linked///zinc finger protein, Y-linked

Oxoglutarate (alpha-ketoglutarate) dehydrogenase (lipoamide)

CDV3 homolog (mouse)

Meningioma expressed antigen 5 (hyaluronidase)

Solute carrier family 7 (cationic amino acid transporter, $\mathrm{y}+$ system), member 6

Component of oligomeric Golgi complex 3

Protein tyrosine phosphatase, non-receptor type 21

Obscurin-like 1

Phosphorylase kinase, gamma 1 (muscle)

LanC lantibiotic synthetase component C-like 1 (bacterial)

Obscurin-like 1

Ubiquitin specific peptidase 47

Structural maintenance of chromosomes 3

Ankyrin repeat and $\mathrm{KH}$ domain containing 1

Kelch repeat and BTB (POZ) domain containing 2

Arginine-glutamic acid dipeptide (RE) repeats

Nuclear factor of activated T-cells, cytoplasmic,

calcineurin-dependent 2 interacting protein

Spire homolog 1 (Drosophila)

Protein phosphatase 1, regulatory (inhibitor) subunit 3B

Versican

Mitogen-activated protein kinase 14

ARP2 actin-related protein 2 homolog (yeast)

Sorbin and SH3 domain containing 1

Son of sevenless homolog 2 (Drosophila)

Mitogen-activated protein kinase 14

Glucosaminyl (N-acetyl) transferase 2, I-branching enzyme (I blood group)

MRNA; cDNA DKFZp451B209 (from clone DKFZp451B209)

ARP2 actin-related protein 2 homolog (yeast)

Syntaxin 16

Non-POU domain containing, octamer-binding

Jumonji, AT rich interactive domain $1 \mathrm{~B}$

Replication protein A1, $70 \mathrm{kd}$

Sorting nexin 13

Neural cell adhesion molecule 1

Ubiquitin protein ligase E3B

Endoplasmic reticulum aminopeptidase 2

Mitogen-activated protein kinase kinase kinase kinase 5

Chromosome 6 open reading frame 166

Prickle homolog 1 (Drosophila)

Erythrocyte membrane protein band 4.1-like 2

Platelet-activating factor acetylhydrolase, isoform Ib, alpha subunit $45 \mathrm{kd}$

Chromosome 1 open reading frame 55

v-erb-b2 erythroblastic leukemia viral oncogene homolog 2, neuro/glioblastoma derived oncogene homolog (avian)

DnaJ (Hsp40) homolog, subfamily C, member 14

Family with sequence similarity 115 , member A///family with sequence similarity 115 , member B

Trans-Golgi network protein 2

Presenilin 1 (Alzheimer disease 3)

\begin{tabular}{lccr}
\multicolumn{1}{c}{ Symbol } & Fold & $\boldsymbol{P}$ value & Gene ID \\
\hline TNFRSF19 & 2.258 down & .0218 & 55504 \\
ZFX///ZFY & 2.256 down & .0216 & $7543 / / / 7544$ \\
OGDH & 2.251 down & .0124 & 4967 \\
CDV3 & 2.251 down & .0111 & 55573 \\
$M G E A 5$ & 2.245 down & .0113 & 10724 \\
SLC7A6 & 2.245 down & .0455 & 9057 \\
& & & \\
COG3 & 2.241 down & .0125 & 83548
\end{tabular}

PTPN21

OBSL1

PHKG1

LANCLI

OBSL1

USP47

SMC3

ANKHD1

KBTBD2

RERE

NFATC2IP

SPIRE1

PPPIR3B

VCAN

MAPK14

ACTR2

SORBS1

SOS2

$M A P K 14$

GCNT2

2.241 down

.0125

83548

2.239 down

.0199

11099

2.238 down

2.236 down

2.234 down

2.229 down

2.227 down

2.226 down

2.225 down

2.225 down

2.224 down

.0324

.0239

.0183

.0282

.00285

.0134

.0259

.0116

.0448

.0151

23363

5260

10314

23363

55031

9126

404734

25948

473

84901

.0146

2.217 down

2.217 down

.0234

.0487

.0377

2.210 down

2.205 down

2.205 down

2.204 down

2.201 down

2.194 down

.0088

.0112

.0404

.0111

.0255

56907

79660

1462

1432

10097

10580

6655

1432

2651

2.193 down

.028

ACTR2

STX16

NONO

JARIDIB

RPAI

SNX13

NCAM1

$U B E 3 B$

ERAP2

MAP $4 K 5$

C6orf166

PRICKLE1

EPB41L2

PAFAHIBI

2.193 down

.0167

10097

2.192 down

2.190 down

.0145

.0255

.0274

.0103

2.185 down

2.183 down

.0124

2.177 down

2.177 down

.0119

.012

2.172 down

.0346

.0111

.0171

2.168 down

2.168 down

.0424

2.168 down

.0116

.0262

Clorf55

ERBB2

2.164 down

.0169

.0132

163859

2.163 down

.0253

DNAJC14

2.163 down

.011

$653199 / / / 9747$

FAM115B

TGOLN2

PSEN1
2.162 down

2.160 down

2.160 down
.0212

.0142
85406

8675

4841

10765

6117

23161

4684

89910

64167

11183

55122

144165

2037

5048

10618

5663 
TABLE E2. Continued

\begin{tabular}{l}
\hline Gene title \\
\hline Cbp/p300-interacting transactivator, with Glu/Asp-rich \\
carboxy-terminal domain, 2 \\
Ubiquitin-like modifier activating enzyme 1 \\
Phosphatidylinositol-4-phosphate 5-kinase, type I, alpha \\
B-cell chronic lymphocytic leukemia/lymphoma 6 (zinc \\
finger protein 51)
\end{tabular}

Zinc finger protein 317

Sorting nexin 13

SUMO1/sentrin/SMT3 specific peptidase 3

Structural maintenance of chromosomes 3

Methionine adenosyltransferase II, alpha

Polymerase (DNA-directed), delta interacting protein 3

Receptor interacting protein kinase 5

Retinoic acid receptor, beta

O-linked N-acetylglucosamine (GlcNAc) transferase

(UDP-N-acetylglucosamine:polypeptide-N-acetylglucosaminyl transferase)

PTPRF interacting protein, binding protein 1 (liprin beta 1)

Trinucleotide repeat containing $6 \mathrm{C}$

FRY-like

Ankyrin repeat and FYVE domain containing 1

DIP2 disco-interacting protein 2 homolog C (Drosophila)

ARP2 actin-related protein 2 homolog (yeast)

Deleted in liver cancer 1

ets variant gene 1

Translocated promoter region (to activated MET oncogene)

Signal transducer and activator of transcription 3

(acute-phase response factor)

Calcium binding protein 39

Glutamine and serine rich 1

Actin binding LIM protein 1

Zinc finger protein 36, C3H type-like 2

Junctional adhesion molecule 3

Golgi autoantigen, golgin subfamily a, 2

Nuclear factor I/A

Cholinergic receptor, muscarinic 2

Ankyrin 3, node of Ranvier (ankyrin G)

Neuroblastoma breakpoint family, member 1

FRY-like

UDP-N-acetyl-alpha-D-galactosamine:polypeptide

$\mathrm{N}$-acetylgalactosaminyltransferase 2 (GalNAc-T2)

MAP/microtubule affinity-regulating kinase 2

Transmembrane 9 superfamily protein member 4

Nucleobindin 1

Rho GTPase activating protein 26

Dynactin 1 (p150, glued homolog, Drosophila)

Ubiquitin specific peptidase 10

Squamous cell carcinoma antigen recognized by $\mathrm{T}$ cells 3

Importin 8

Hepatocyte growth factor-regulated tyrosine kinase substrate

Solute carrier family 8 (sodium/calcium exchanger), member 1

Protein tyrosine phosphatase, non-receptor type 12

Chloride intracellular channel 4

FK506 binding protein 15, $133 \mathrm{kd}$

Insulin-like growth factor binding protein 5

\begin{tabular}{cccr} 
Symbol & Fold & $\boldsymbol{P}$ value & Gene ID \\
\hline CITED2 & 2.160 down & .0323 & 10370
\end{tabular}

$\begin{array}{lllr}\text { UBA1 } & 2.159 \text { down } & .0234 & 7317 \\ \text { PIP5K1A } & 2.157 \text { down } & .0366 & 8394 \\ \text { BCL6 } & 2.156 \text { down } & .0463 & 604 \\ & & & \\ \text { ZNF317 } & 2.155 \text { down } & .0206 & 57693 \\ \text { SNX13 } & 2.153 \text { down } & .0236 & 23161 \\ \text { SENP3 } & 2.150 \text { down } & .0127 & 26168 \\ \text { SMC3 } & 2.149 \text { down } & .0115 & 9126 \\ \text { MAT2A } & 2.148 \text { down } & .0187 & 4144 \\ \text { POLDIP3 } & 2.145 \text { down } & .0133 & 84271 \\ \text { RIPK5 } & 2.139 \text { down } & .012 & 25778 \\ \text { RARB } & 2.137 \text { down } & .0307 & 5915 \\ \text { OGT } & 2.136 \text { down } & .0154 & 8473\end{array}$

2.136 down

.012

8496

TNRC6C

FRYL

ANKFY1

$D I P 2 C$

ACTR2

DLCl

ETV1

TPR

STAT3

2.136 down

.0124

57690

2.134 down

.0128

285527

2.134 down

.0125

51479

2.134 down

.0113

22982

10097

2.133 down

.015

10395

2.131 down

.0206

2115

7175

6774

CAB39

QSER1

ABLIMI

ZFP36L2

JAM3

GOLGA2

NFIA

CHRM2

ANK3

NBPF1

FRYL

GALNT2

2.131 down

.0243

.0187

51719

2.129 down

.0217

79832

2.129 down

.0119

.017

.0394

3983

2.125 down

2.122 down

.00921

678

83700

2801

4774

1129

288

149013

285527

2590

MARK2

TM9SF4

NUCB1

ARHGAP26

DCTN1

USP10

SART3

IPO8

HGS

SLC8A1

PTPN12

CLIC4

FKBP15

2.121 down

2.120 down

.0102

.0365

.0114

2.115 down

.0254

.0158

.0376

2011

2.113 down

.0212

9777

2.109 down

.0258

4924

2.109 down

.0228

23092

2.109 down

.0157

.0209

1639

9100

.0113

9733

2.105 down

2.104 down

.0137

.0206

.0122

10526

9146

6546

5782

.041

25932

IGFBP5

2.102 down

2.100 down

2.099 down

2.097 down
.026

.0249

.0263 


\section{Gene title}

ATPase, $\mathrm{H}^{+}$transporting, lysosomal $70 \mathrm{kd}, \mathrm{V} 1$ subunit A

Neighbor of BRCA1 gene 1///similar to neighbor of BRCA1 gene 1

TEA domain family member 2

Cytokine-like nuclear factor n-pac

CCR4-NOT transcription complex, subunit 1

Myosin XVIIIB

Leucine-rich repeats and immunoglobulin-like domains 1

Zinc finger protein 514

Apolipoprotein E

Minichromosome maintenance complex component 7

Arsenate resistance protein 2

$\mathrm{N}$-acetyltransferase 11

GM2 ganglioside activator

Jun D proto-oncogene

Mitogen-activated protein kinase kinase kinase 2

Karyopherin alpha 1 (importin alpha 5)

YY1 transcription factor

KDEL (Lys-Asp-Glu-Leu) endoplasmic reticulum protein retention receptor 1

Prolyl endopeptidase-like

O-linked N-acetylglucosamine (GlcNAc) transferase (UDP-N-acetylglucosamine:polypeptide- $\mathrm{N}$-acetylglucosaminyl transferase)

Insulin-like growth factor 2 receptor

Zinc finger protein 275

Zinc finger, MYM-type 2

GTPase activating protein (SH3 domain) binding protein 2

CDNA FLJ33081 fis, clone TRACH2000321

\section{KIAA0430}

ets variant gene 1

Leucine rich repeat (in FLII) interacting protein 2

Endothelial differentiation, lysophosphatidic acid G-protein-coupled receptor, 7

Obscurin-like 1

Retinoblastoma-like 2 (p130)

Ubiquitin-conjugating enzyme E2G 2 (UBC7 homolog, yeast)

Calcium channel, voltage-dependent, alpha 2/delta subunit 1

Uridine-cytidine kinase 1-like 1

Bromodomain containing 2

Tripartite motif-containing 56

AF4/FMR2 family, member 4

Ubiquitously transcribed tetratricopeptide repeat, $\mathrm{X}$ chromosome

Spectrin, beta, nonerythrocytic 1

Striatin, calmodulin binding protein

Uridine-cytidine kinase 1

Solute carrier family 2 (facilitated glucose transporter), member 11

Hypothetical LOC552889

Peroxisome proliferator-activated receptor alpha

Chromosome 10 open reading frame 46

\begin{tabular}{lccr}
\multicolumn{1}{c}{ Symbol } & Fold & $\boldsymbol{P}$ value & Gene ID \\
\hline ATP6V1A & 2.097 down & .0143 & 523 \\
& & & \\
LOC727732//I & 2.096 down & .0126 & $4077 / / / 727732$ \\
$\quad$ NBR1 & & & \\
TEAD2 & 2.096 down & .0399 & 8463 \\
N-PAC & 2.095 down & .0225 & 84656 \\
CNOT1 & 2.093 down & .0122 & 23019 \\
MYO18B & 2.090 down & .0218 & 84700 \\
LRIG1 & 2.090 down & .0134 & 26018 \\
ZNF514 & 2.090 down & .0335 & 84874 \\
APOE & 2.088 down & .0284 & 348 \\
$M C M 7$ & 2.086 down & .0258 & 4176 \\
ARS2 & 2.082 down & .0209 & 51593 \\
NAT11 & 2.081 down & .0317 & 79829 \\
GM2A & 2.079 down & .0372 & 2760 \\
JUND & 2.079 down & .0218 & 3727 \\
$M A P 3 K 2$ & 2.077 down & .00667 & 10746 \\
KPNA1 & 2.076 down & .0169 & 3836 \\
$Y Y 1$ & 2.075 down & .048 & 7528 \\
KDELR1 & 2.074 down & .0175 & 10945 \\
PREPL & & & \\
OGT & 2.072 down & .0113 & 9581 \\
& 2.072 down & .0136 & 8473
\end{tabular}

$I G F 2 R$

ZNF275

ZMYM2

G3BP2

KIAA0430

ETV1

LRRFIP2

EDG7

2.072 down

2.070 down

2.069 down

.0102

.0462

.0255

.0134

2.069 down $\quad .0287$

2.068 down $\quad .0136$

2.068 down $\quad .0125$

2.067 down $\quad .0162$

2.066 down

.0437

OBSL1

RBL2

UBE2G2

2.066 down

.0243

.0175

.0125

3482

10838

7750

9908

9665

2115

9209

23566

23363

5934

7327

CACNA2D1

2.062 down

.0237

781

UCKL1

BRD2

TRIM56

AFF4

UTX

2.062 down

.0344

2.059 down

.0473

.0129

2.059 down $\quad .0442$

2.058 down $\quad .0299$

.017

2.057 down

.0113

.0281

2.056 down

2.055 down

.0197

2.053 down

.0136

.0151

2.051 down

2.051 down

.0163
54963

6046

81844

27125

7403

6711

6801

83549

66035

552889

5465

143384 
TABLE E2. Continued

\begin{tabular}{|c|c|c|c|c|}
\hline Gene title & Symbol & Fold & $P$ value & Gene ID \\
\hline Outer dense fiber of sperm tails 2 & $O D F 2$ & 2.049 down & .0114 & 4957 \\
\hline $\begin{array}{l}\text { O-linked N-acetylglucosamine (GlcNAc) transferase } \\
\text { (UDP-N-acetylglucosamine:polypeptide-N-acetylglucosaminyl } \\
\text { transferase) }\end{array}$ & $O G T$ & 2.048 down & .016 & 8473 \\
\hline Janus kinase 1 (a protein tyrosine kinase) & $J A K 1$ & 2.047 down & .0312 & 3716 \\
\hline Structure specific recognition protein 1 & SSRP1 & 2.047 down & .0211 & 6749 \\
\hline Glutamyl-prolyl-tRNA synthetase & $E P R S$ & 2.047 down & .0149 & 2058 \\
\hline Karyopherin alpha 4 (importin alpha 3) & KPNA4 & 2.045 down & .0126 & 3840 \\
\hline MAD1 mitotic arrest deficient-like 1 (yeast) & $M A D 1 L 1$ & 2.045 down & .0331 & 8379 \\
\hline Zinc finger CCCH-type containing $11 \mathrm{~A}$ & ZC $3 H 11 A$ & 2.045 down & .0113 & 9877 \\
\hline Ubiquitin specific peptidase 25 & USP25 & 2.044 down & .0103 & 29761 \\
\hline Tribbles homolog 2 (Drosophila) & TRIB2 & 2.044 down & .00966 & 28951 \\
\hline Adenomatous polyposis coli & $A P C$ & 2.043 down & .0111 & 324 \\
\hline Centrosomal protein $68 \mathrm{kd}$ & CEP68 & 2.040 down & .0174 & 23177 \\
\hline Protein phosphatase 1, regulatory (inhibitor) subunit 12B & $P P P 1 R 12 B$ & 2.040 down & .012 & 4660 \\
\hline v-crk sarcoma virus CT10 oncogene homolog (avian) & $C R K$ & 2.037 down & .022 & 1398 \\
\hline Protein phosphatase 2 , regulatory subunit $\mathrm{B}^{\prime}$, delta isoform & $P P P 2 R 5 D$ & 2.034 down & .0319 & 5528 \\
\hline GATA zinc finger domain containing 1 & GATAD1 & 2.033 down & .0295 & 57798 \\
\hline Dipeptidyl-peptidase 8 & $D P P 8$ & 2.031 down & .0442 & 54878 \\
\hline Mitochondrial tumor suppressor 1 & MTUS1 & 2.030 down & .0258 & 57509 \\
\hline Ubiquitination factor E4B (UFD2 homolog, yeast) & $U B E 4 B$ & 2.028 down & .0118 & 10277 \\
\hline Fusion (involved in $\mathrm{t}(12 ; 16)$ in malignant liposarcoma) & FUS & 2.027 down & .0394 & 2521 \\
\hline Hippocalcin-like 1 & HPCAL1 & 2.027 down & .0449 & 3241 \\
\hline ATP-binding cassette, sub-family C (CFTR/MRP), member 9 & $A B C C 9$ & 2.027 down & .0125 & 10060 \\
\hline Protein tyrosine phosphatase, non-receptor type 21 & $P T P N 21$ & 2.025 down & .0234 & 11099 \\
\hline Ubiquitin specific peptidase 34 & USP34 & 2.024 down & .0159 & 9736 \\
\hline DEAD (Asp-Glu-Ala-Asp) box polypeptide 3, X-linked & $D D X 3 X$ & 2.024 down & .0203 & 1654 \\
\hline Phosphatidylinositol binding clathrin assembly protein & PICALM & 2.023 down & .0158 & 8301 \\
\hline Transportin 3 & TNPO3 & 2.022 down & .0166 & 23534 \\
\hline Non-POU domain containing, octamer-binding & NONO & 2.022 down & .0192 & 4841 \\
\hline ORM1-like 3 (S cerevisiae) & ORMDL3 & 2.021 down & .014 & 94103 \\
\hline Mitogen-activated protein kinase kinase kinase kinase 4 & $M A P 4 K 4$ & 2.021 down & .0371 & 9448 \\
\hline Tribbles homolog 1 (Drosophila) & TRIBI & 2.021 down & .0206 & 10221 \\
\hline WD repeat domain 6 & WDR6 & 2.020 down & .0135 & 11180 \\
\hline Aspartate beta-hydroxylase & $A S P H$ & 2.020 down & .00586 & 444 \\
\hline Zinc finger protein 45 & ZNF45 & 2.019 down & .0125 & 7596 \\
\hline SET domain containing 5 & SETD5 & 2.019 down & .0266 & 55209 \\
\hline Eukaryotic translation initiation factor $4 \mathrm{E}$ nuclear import factor 1 & EIF4ENIF1 & 2.017 down & .0142 & 56478 \\
\hline High-density lipoprotein binding protein (vigilin) & $H D L B P$ & 2.013 down & .0162 & 3069 \\
\hline $\begin{array}{l}\text { Mannosyl (alpha-1,3-)-glycoprotein beta-1, } \\
\text { 4-N-acetylglucosaminyltransferase, isozyme B }\end{array}$ & $M G A T 4 B$ & 2.012 down & .0175 & 11282 \\
\hline AT rich interactive domain $1 \mathrm{~A}$ (SWI-like) & ARIDIA & 2.012 down & .0426 & 8289 \\
\hline Alkylglycerone phosphate synthase & $A G P S$ & 2.011 down & .00981 & 8540 \\
\hline MLCK protein & $M L C K$ & 2.010 down & .0158 & 91807 \\
\hline FYVE, RhoGEF and PH domain containing 6 & FGD6 & 2.009 down & .0163 & 55785 \\
\hline Cytoplasmic FMR1 interacting protein 2 & CYFIP2 & 2.007 down & .0392 & 26999 \\
\hline Acyl-CoA thioesterase 11 & ACOT11 & 2.003 down & .0417 & 26027 \\
\hline Ubiquitin specific peptidase 11 & USP11 & 2.001 down & .0306 & 8237 \\
\hline Zinc finger protein $395 / / / F-b o x$ protein 16 & $\begin{array}{r}\text { FBXO16//I } \\
\text { ZNF395 }\end{array}$ & 2.000 down & .035 & $\begin{array}{c}157574 / / / \\
55893\end{array}$ \\
\hline Adrenergic, alpha-1A-, receptor & ADRAlA & 1.998 down & .0404 & 148 \\
\hline M-phase phosphoprotein 9 & МРHOSPH9 & 1.996 down & .0239 & 10198 \\
\hline Nudix (nucleoside diphosphate linked moiety X)-type motif 21 & NUDT21 & 1.995 down & .0167 & 11051 \\
\hline Kruppel-like factor 3 (basic) & $K L F 3$ & 1.993 down & .0169 & 51274 \\
\hline Synovial sarcoma translocation, chromosome 18 & SS18 & 1.992 down & .0185 & 6760 \\
\hline
\end{tabular}




\begin{tabular}{|c|c|c|c|c|}
\hline Gene title & Symbol & Fold & $P$ value & Gene ID \\
\hline Exocyst complex component 5 & EXOC5 & 1.991 down & .016 & 10640 \\
\hline Rabaptin, RAB GTPase binding effector protein 1 & $R A B E P 1$ & 1.990 down & .0482 & 9135 \\
\hline PRP4 pre-mRNA processing factor 4 homolog (yeast) & PRPF4 & 1.990 down & .0206 & 9128 \\
\hline CDNA FLJ10151 fis, clone HEMBA1003402 & & 1.986 down & .0136 & \\
\hline CDNA clone IMAGE:5263531 & & 1.986 down & .0114 & \\
\hline SH3-domain GRB2-like endophilin B2 & SH3GLB2 & 1.985 down & .0301 & 56904 \\
\hline Serologically defined colon cancer antigen 1 & SDCCAG1 & 1.985 down & .0111 & 9147 \\
\hline Zinc finger protein 398 & ZNF398 & 1.981 down & .0365 & 57541 \\
\hline Cytochrome b reductase 1 & $C Y B R D 1$ & 1.980 down & .0237 & 79901 \\
\hline Transformation/transcription domain-associated protein & TRRAP & 1.977 down & .0235 & 8295 \\
\hline SON DNA binding protein & SON & 1.975 down & .0125 & 6651 \\
\hline Nucleoporin $133 \mathrm{kd}$ & NUP133 & 1.975 down & .0187 & 55746 \\
\hline Discoidin domain receptor family, member 2 & $D D R 2$ & 1.973 down & .0112 & 4921 \\
\hline A kinase (PRKA) anchor protein 8-like & $A K A P 8 L$ & 1.971 down & .0291 & 26993 \\
\hline Lanosterol synthase (2,3-oxidosqualene-lanosterol cyclase) & $L S S$ & 1.971 down & .0347 & 4047 \\
\hline dpy-19-like 1 (C elegans) & DPY19L1 & 1.968 down & .0174 & 23333 \\
\hline Dystonin & DST & 1.967 down & .00579 & 667 \\
\hline $\begin{array}{l}\text { Splicing factor, arginine/serine-rich } 8 \\
\quad \text { (suppressor-of-white-apricot homolog, Drosophila) }\end{array}$ & SFRS8 & 1.967 down & .0239 & 6433 \\
\hline NGFI-A binding protein 1 (EGR1 binding protein 1) & $N A B 1$ & 1.965 down & .0132 & 4664 \\
\hline Exocyst complex component 7 & EXOC7 & 1.963 down & .0278 & 23265 \\
\hline $\begin{array}{l}\text { Syntrophin, beta } 2 \text { (dystrophin-associated protein } \mathrm{A} 1,59 \mathrm{kd} \text {, } \\
\text { basic component } 2 \text { ) }\end{array}$ & SNTB2 & 1.962 down & .0196 & 6645 \\
\hline SEC63 homolog (S cerevisiae) & SEC63 & 1.961 down & .0142 & 11231 \\
\hline $\begin{array}{l}\text { SHC (Src homology } 2 \text { domain containing) transforming } \\
\text { protein } 1\end{array}$ & $S H C 1$ & 1.960 down & .0129 & 6464 \\
\hline Engulfment and cell motility 2 & ELMO2 & 1.960 down & .021 & 63916 \\
\hline Chromosome 1 open reading frame 25 & Clorf 25 & 1.959 down & .0309 & 81627 \\
\hline Glutamate-ammonia ligase (glutamine synthetase) & $G L U L$ & 1.958 down & .0355 & 2752 \\
\hline MYST histone acetyltransferase (monocytic leukemia) 4 & MYST4 & 1.957 down & .0229 & 23522 \\
\hline FOS-like antigen 2 & FOSL2 & 1.957 down & .0326 & 2355 \\
\hline KIAA0692 & KIAA0692 & 1.957 down & .025 & 23141 \\
\hline Potassium channel tetramerization domain containing 20 & KCTD20 & 1.955 down & .028 & 222658 \\
\hline WD repeat domain 26 & WDR26 & 1.955 down & .0125 & 80232 \\
\hline Senataxin & SETX & 1.953 down & .0121 & 23064 \\
\hline Trinucleotide repeat containing 6B & $T N R C 6 B$ & 1.951 down & .00655 & 23112 \\
\hline Transmembrane 9 superfamily member 1 & TM9SF1 & 1.951 down & .0301 & 10548 \\
\hline Family with sequence similarity 108, member B1 & FAM108B1 & 1.948 down & .0404 & 51104 \\
\hline Transmembrane protein $30 \mathrm{~A}$ & TMEM30A & 1.948 down & .0137 & 55754 \\
\hline $\begin{array}{l}\text { CTD (carboxy-terminal domain, RNA polymerase II, } \\
\text { polypeptide A) small phosphatase like } 2\end{array}$ & CTDSPL2 & 1.948 down & .0238 & 51496 \\
\hline Zinc finger protein 24 & ZNF24 & 1.947 down & .011 & 7572 \\
\hline HLA-B associated transcript 3 & BAT3 & 1.947 down & .0299 & 7917 \\
\hline Chromosome 21 open reading frame 33 & C21orf33 & 1.946 down & .0321 & 8209 \\
\hline Protein kinase $\mathrm{C}$ substrate $80 \mathrm{~K}-\mathrm{H}$ & PRKCSH & 1.945 down & .0205 & 5589 \\
\hline Pleckstrin homology, Sec7 and coiled-coil domains 3 & PSCD3 & 1.943 down & .0134 & 9265 \\
\hline BCL2-antagonist of cell death & $B A D$ & 1.941 down & .0326 & 572 \\
\hline A kinase (PRKA) anchor protein 10 & AKAP10 & 1.941 down & .0355 & 11216 \\
\hline Sorbin and SH3 domain containing 3 & SORBS3 & 1.939 down & .0162 & 10174 \\
\hline v-akt murine thymoma viral oncogene homolog 2 & $A K T 2$ & 1.939 down & .035 & 208 \\
\hline $\begin{array}{l}\text { Myeloid/lymphoid or mixed-lineage leukemia } \\
\text { (trithorax homolog, Drosophila) }\end{array}$ & $M L L$ & 1.939 down & .0264 & 4297 \\
\hline Integrin, alpha 7 & ITGA7 & 1.938 down & .0256 & 3679 \\
\hline $\begin{array}{l}\text { Ankyrin repeat and } \mathrm{KH} \text { domain containing } \\
\text { 1///ANKHD1-EIF4EBP3 }\end{array}$ & $\begin{array}{l}A N K H D 1 / / / \\
\text { ANKHD1- } \\
\text { EIF4EBP3 }\end{array}$ & 1.938 down & .0401 & $\begin{array}{c}404734 / / / \\
54882\end{array}$ \\
\hline
\end{tabular}


TABLE E2. Continued

\begin{tabular}{|c|c|c|c|c|}
\hline Gene title & Symbol & Fold & $P$ value & Gene ID \\
\hline CCR4-NOT transcription complex, subunit 4 & CNOT4 & 1.937 down & .0261 & 4850 \\
\hline CDNA FLJ38461 fis, clone FEBRA2020977 & & 1.935 down & .0168 & \\
\hline Membrane-associated ring finger $(\mathrm{C} 3 \mathrm{HC} 4) 6$ & 7-Mar & 1.935 down & .00973 & 10299 \\
\hline Zinc finger protein 540 & ZNF540 & 1.934 down & .024 & 163255 \\
\hline Solute carrier family 30 (zinc transporter), member 5 & SLC30A5 & 1.934 down & .00814 & 64924 \\
\hline Ral guanine nucleotide dissociation stimulator & $R A L G D S$ & 1.934 down & .0212 & 5900 \\
\hline Mitogen-activated protein kinase 1 & $M A P K 1$ & 1.933 down & .0124 & 5594 \\
\hline Small G protein signaling modulator 3 & $S G S M 3$ & 1.932 down & .0354 & 27352 \\
\hline Intracisternal A particle-promoted polypeptide & $I P P$ & 1.932 down & .0337 & 3652 \\
\hline Mediator complex subunit 23 & MED23 & 1.931 down & .0242 & 9439 \\
\hline $\begin{array}{l}\text { Bone morphogenetic protein receptor, type II } \\
\text { (serine/threonine kinase) }\end{array}$ & $B M P R 2$ & 1.929 down & .0111 & 659 \\
\hline MOCO sulphurase C-terminal domain containing 2 & MOSC2 & 1.928 down & .00932 & 54996 \\
\hline $\begin{array}{l}\text { Myeloid/lymphoid or mixed-lineage leukemia } \\
\text { (trithorax homolog, Drosophila) }\end{array}$ & $M L L$ & 1.927 down & .0172 & 4297 \\
\hline Troponin T type 2 (cardiac) & TNNT2 & 1.926 down & .0352 & 7139 \\
\hline ATPase, $\mathrm{H}^{+}$transporting, lysosomal V0 subunit a1 & ATP6V0A1 & 1.925 down & .0372 & 535 \\
\hline RAD23 homolog A (S cerevisiae) & $R A D 23 A$ & 1.924 down & .0205 & 5886 \\
\hline Nuclear receptor coactivator 3 & NCOA3 & 1.924 down & .0496 & 8202 \\
\hline Myelin basic protein & $M B P$ & 1.924 down & .0167 & 4155 \\
\hline $\begin{array}{l}\text { Solute carrier family } 33 \text { (acetyl-CoA transporter), } \\
\text { member } 1\end{array}$ & SLC33A1 & 1.923 down & .0112 & 9197 \\
\hline T-box 5 & $T B X 5$ & 1.923 down & .0203 & 6910 \\
\hline DEAH (Asp-Glu-Ala-His) box polypeptide 9 & DHX9 & 1.923 down & .0112 & 1660 \\
\hline Intraflagellar transport 122 homolog (Chlamydomonas) & IFT122 & 1.922 down & .0247 & 55764 \\
\hline Calnexin & CANX & 1.921 down & .0103 & 821 \\
\hline Rab and DnaJ domain containing & $R B J$ & 1.921 down & .03 & 51277 \\
\hline $\begin{array}{l}\text { Hydroxyacyl-coenzyme A dehydrogenase/3-ketoacyl- } \\
\text { coenzyme A thiolase/enoyl-coenzyme A hydratase } \\
\text { (trifunctional protein), alpha subunit }\end{array}$ & $H A D H A$ & 1.921 down & .0375 & 3030 \\
\hline Dystonin & DST & 1.919 down & .0112 & 667 \\
\hline Phosphoinositide-3-kinase, class 2, alpha polypeptide & $P I K 3 C 2 A$ & 1.919 down & .0216 & 5286 \\
\hline ADAM metallopeptidase domain 10 & ADAM10 & 1.918 down & .0433 & 102 \\
\hline Fibronectin type III domain containing $3 \mathrm{~A}$ & $F N D C 3 A$ & 1.918 down & .00672 & 22862 \\
\hline Spire homolog 1 (Drosophila) & SPIRE1 & 1.917 down & .0109 & 56907 \\
\hline RAS and EF-hand domain containing & RASEF & 1.917 down & .0401 & 158158 \\
\hline Phosphodiesterase 1C, calmodulin-dependent $70 \mathrm{kd}$ & PDEIC & 1.916 down & .0136 & 5137 \\
\hline Ring finger protein $19 \mathrm{~A}$ & $R N F 19 A$ & 1.916 down & .0112 & 25897 \\
\hline alkB, alkylation repair homolog 5 (E coli) & $A L K B H 5$ & 1.916 down & .0208 & 54890 \\
\hline zer-1 homolog (C elegans) & ZERI & 1.915 down & .0125 & 10444 \\
\hline $\begin{array}{l}\text { Obscurin, cytoskeletal calmodulin and titin-interacting } \\
\text { RhoGEF }\end{array}$ & $O B S C N$ & 1.914 down & .0387 & 84033 \\
\hline Zinc finger with KRAB and SCAN domains 1 & ZKSCAN1 & 1.914 down & .0142 & 7586 \\
\hline Chloride intracellular channel 5 & CLIC5 & 1.913 down & .0391 & 53405 \\
\hline WW domain containing adaptor with coiled-coil & $W A C$ & 1.913 down & .00669 & 51322 \\
\hline Wolfram syndrome 1 (wolframin) & WFS1 & 1.912 down & .0492 & 7466 \\
\hline Son of sevenless homolog 1 (Drosophila) & SOS1 & 1.911 down & .0448 & 6654 \\
\hline Cytoskeleton associated protein 5 & CKAP5 & 1.909 down & .0109 & 9793 \\
\hline Cullin 4B & CULAB & 1.909 down & .0204 & 8450 \\
\hline Paired related homeobox 1 & PRRXI & 1.908 down & .0262 & 5396 \\
\hline $\begin{array}{l}\text { Minichromosome maintenance complex component } 3 \\
\text { associated protein }\end{array}$ & МCMЗАP & 1.907 down & .0424 & 8888 \\
\hline Sp1 transcription factor & $S P 1$ & 1.906 down & .0327 & 6667 \\
\hline Nuclear transcription factor $\mathrm{Y}$, gamma & $N F Y C$ & 1.904 down & .0239 & 4802 \\
\hline
\end{tabular}




\begin{tabular}{l} 
Gene title \\
\hline v-rel reticuloendotheliosis viral oncogene homolog A, \\
nuclear factor of kappa light polypeptide gene \\
enhancer in B-cells 3, p65 (avian)
\end{tabular}

Chromosome 5 open reading frame 22

MYST histone acetyltransferase (monocytic leukemia) 4

Iroquois homeobox 5

Epoxide hydrolase 1, microsomal (xenobiotic)

Microtubule associated monoxygenase, calponin and

LIM domain containing 3///similar to Protein MICAL-3

Putative homeodomain transcription factor 2

Mitogen-activated protein kinase kinase kinase 3

Zinc finger protein 227

Membrane associated guanylate kinase, WW and PDZ domain containing 2

Bicaudal D homolog 2 (Drosophila)

Adducin 1 (alpha)

Plexin B1

Adenylate cyclase 9

Zinc finger CCCH-type containing 7A

TOX high mobility group box family member

4///similar to Epidermal Langerhans cell protein LCP1

Nucleoporin $98 \mathrm{kd}$

Platelet derived growth factor $\mathrm{C}$

Block of proliferation 1///similar to block of proliferation 1

Obscurin, cytoskeletal calmodulin and titin-interacting RhoGEF

guanine nucleotide binding protein ( $\mathrm{G}$ protein), beta 5

Protein tyrosine phosphatase, nonreceptor type 21

Adaptor-related protein complex 3, delta 1 subunit

$\mathrm{v}$-akt murine thymoma viral oncogene homolog 2

Solute carrier family 25 (mitochondrial carrier; adenine nucleotide translocator), member 6

Zinc finger, DHHC-type containing 5

Latent transforming growth factor beta binding protein 1

Rho GTPase activating protein 26

ATPase, class I, type 8B, member 2

Tuberous sclerosis 2

ATPase, class VI, type 11A

RIO kinase 3 (yeast)

Golgi apparatus protein 1

Nicotinamide nucleotide transhydrogenase

Chromosome 19 open reading frame 6

Bromodomain containing 2

Purine-rich element binding protein B

Glutathione reductase

ADP-ribosylation factor guanine nucleotide-exchange factor 1 (brefeldin A-inhibited)

ADP-ribosylation factor interacting protein 1 (arfaptin 1)

Rhotekin

Jumonji domain containing 3, histone lysine demethylase

Zinc finger and SCAN domain containing 18

Kelch repeat and BTB (POZ) domain containing 4

PRP6 pre-mRNA processing factor 6 homolog (S cerevisiae)

CCR4-NOT transcription complex, subunit 3

Symbol

RELA

C5orf22

MYST4

IRX5

EPHX1

LOC731210

//MICAL3

PHTF2

$M A P 3 K 3$

ZNF227

MAGI2

BICD2

$A D D 1$

PLXNB1

$A D C Y 9$

ZC $3 H 7 \mathrm{~A}$

LOC285412

///TOX4

NUP98

PDGFC

BOP1/II

LOC727967

OBSCN

GNB5

PTPN21

AP3D1

AKT2

SLC25A6

ZDHHC5

LTBP1

ARHGAP26

ATP $8 B 2$

TSC2

ATP11A

RIOK3

GLG1

NNT

C19orf6

BRD2

PURB

GSR

ARFGEF1

ARFIPI

RTKN

JMJD3

ZSCAN18

KBTBD4

PRPF6

CNOT3
1.903 down

1.903 down

1.903 down

1.903 down

1.903 down

1.902 down

1.901 down

1.900 down

1.900 down

1.900 down

1.900 down

1.900 down

1.899 down

1.899 down

1.899 down

1.898 down

1.897 down

1.897 down

1.896 down

1.894 down

1.894 down

1.890 down

1.889 down

1.889 down

1.888 down

1.888 down

1.887 down

1.885 down

1.885 down

1.884 down

1.883 down

1.882 down

1.880 down

1.879 down

1.879 down

1.879 down

1.879 down

1.877 down

1.877 down

1.876 down

1.875 down

1.874 down

1.873 down

1.872 down

1.871 down
.0126

.0135

.0313

.0158

.0487

.04

.0458

.0262

.035

.0232

.0136

.034

.0163

.0118

.0263

.0212

.0461

.0448

.0392

.0396

.0278

.0112

.0174

.0291

.0136

.0126

.0245

.0109

.0281

.0107

.0238

.0234

.0106

.0125

.0228

.0281

.00928

.00671

.0116

.0109

.0102

.0223

.044

.0132

.0226
55322

23522

10265

2052

$57553 / / /$

731210

57157

4215

7770

9863

23299

118

5364

115

29066

285412///

9878

4928

56034

23246///

727967

84033

10681

11099

8943

208

293

25921

4052

23092

57198

7249

23250

8780

2734

23530

91304

6046

5814

2936

10565

27236

6242

23135

65982

55709

24148

4849 
TABLE E2. Continued

\begin{tabular}{|c|c|c|c|c|}
\hline Gene title & Symbol & Fold & $P$ value & Gene ID \\
\hline Zinc finger, RAN-binding domain containing 1 & ZRANBI & 1.870 down & .0289 & 54764 \\
\hline Glucosidase, alpha; neutral $\mathrm{AB}$ & $G A N A B$ & 1.870 down & .0149 & 23193 \\
\hline $\begin{array}{l}\text { Protein tyrosine phosphatase, receptor type, } \\
\text { f polypeptide (PTPRF), } \\
\text { interacting protein (liprin), alpha } 1\end{array}$ & PPFIAI & 1.870 down & .0281 & 8500 \\
\hline Vitamin K epoxide reductase complex, subunit 1-like 1 & VKORCIL1 & 1.869 down & .0114 & 154807 \\
\hline Ring finger and $\mathrm{CCCH}$-type zinc finger domains 2 & $\mathrm{RC} 3 \mathrm{H} 2$ & 1.869 down & .0112 & 54542 \\
\hline F-box and leucine-rich repeat protein 15 & $F B X L 15$ & 1.869 down & .0287 & 79176 \\
\hline Zinc finger, FYVE domain containing 9 & ZFYVE9 & 1.869 down & .0129 & 9372 \\
\hline Transcribed locus & & 1.867 down & .0217 & \\
\hline Trinucleotide repeat containing $6 \mathrm{~B}$ & TNRC6B & 1.867 down & .0128 & 23112 \\
\hline Anterior pharynx defective 1 homolog A (C elegans) & APH1A & 1.867 down & .0317 & 51107 \\
\hline Protein phosphatase 5 , catalytic subunit & PPP5C & 1.866 down & .0448 & 5536 \\
\hline Zinc finger protein 289 , ID1 regulated & ZNF289 & 1.866 down & .0462 & 84364 \\
\hline $\begin{array}{l}\text { UDP-N-acetyl-alpha-D-galactosamine:polypeptide } \\
\text { N-acetylgalactosaminyltransferase } 2 \text { (GalNAc-T2) }\end{array}$ & GALNT2 & 1.865 down & .0191 & 2590 \\
\hline Solute carrier family 25 , member 30 & $S L C 25 A 30$ & 1.864 down & .0372 & 253512 \\
\hline Kelch-like 23 (Drosophila) & KLHL23 & 1.864 down & .0281 & 151230 \\
\hline $\begin{array}{l}\text { RAB3 GTPase activating protein subunit } 2 \\
\text { (non-catalytic) }\end{array}$ & $R A B 3 G A P 2$ & 1.862 down & .0129 & 25782 \\
\hline Ring finger and $\mathrm{CCCH}$-type zinc finger domains 2 & $\mathrm{RC} 3 \mathrm{H} 2$ & 1.861 down & .0128 & 54542 \\
\hline Phospholipase C, beta 4 & PLCB4 & 1.859 down & .016 & 5332 \\
\hline Glucosidase, beta (bile acid) 2 & $G B A 2$ & 1.858 down & .0134 & 57704 \\
\hline Cyclin-dependent kinase inhibitor 1C (p57, Kip2) & $C D K N 1 C$ & 1.858 down & .0266 & 1028 \\
\hline WWC family member 3 & $W W C 3$ & 1.857 down & .0109 & 55841 \\
\hline Tripeptidyl peptidase I & $T P P 1$ & 1.856 down & .0294 & 1200 \\
\hline CD99 molecule-like 2 & CD99L2 & 1.855 down & .0203 & 83692 \\
\hline Zinc finger protein 655 & ZNF655 & 1.853 down & .0226 & 79027 \\
\hline Actin filament associated protein 1-like 1 & $A F A P 1 L 1$ & 1.853 down & .016 & 134265 \\
\hline Eukaryotic translation initiation factor $4 \mathrm{~B}$ & $E I F 4 B$ & 1.852 down & .0112 & 1975 \\
\hline p21 (CDKN1A)-activated kinase 2 & $P A K 2$ & 1.852 down & .0125 & 5062 \\
\hline Poliovirus receptor & $P V R$ & 1.852 down & .00712 & 5817 \\
\hline RAB3 GTPase activating protein subunit 1 (catalytic) & $R A B 3 G A P 1$ & 1.852 down & .0274 & 22930 \\
\hline Interleukin enhancer binding factor $3,90 \mathrm{kd}$ & $I L F 3$ & 1.851 down & .0116 & 3609 \\
\hline Chromosome 6 open reading frame 106 & C6orf106 & 1.850 down & .03 & 64771 \\
\hline Purine-rich element binding protein A & PURA & 1.850 down & .0384 & 5813 \\
\hline Wolf-Hirschhorn syndrome candidate 1-like 1 & WHSClL1 & 1.849 down & .0167 & 54904 \\
\hline Fem-1 homolog b (C elegans) & FEM1B & 1.849 down & .0214 & 10116 \\
\hline Jun oncogene & $J U N$ & 1.848 down & .0243 & 3725 \\
\hline NDRG family member 2 & $N D R G 2$ & 1.848 down & .0415 & 57447 \\
\hline Protocadherin gamma subfamily A, 1 & PCDHGAl & 1.847 down & .0112 & 9708 \\
\hline $\begin{array}{l}\text { Solute carrier family } 6 \text { (neurotransmitter transporter, } \\
\text { creatine), member } 8\end{array}$ & SLC6A8 & 1.847 down & .0266 & 6535 \\
\hline Upstream binding transcription factor, RNA polymerase I & $U B T F$ & 1.847 down & .0227 & 7343 \\
\hline Zer-1 homolog (C elegans) & ZERI & 1.846 down & .0166 & 10444 \\
\hline $\begin{array}{l}\text { Prion protein (p27-30) (Creutzfeldt-Jakob disease, } \\
\text { Gerstmann-Strausler-Scheinker syndrome, } \\
\text { fatal familial insomnia) }\end{array}$ & $P R N P$ & 1.845 down & .0168 & 5621 \\
\hline General transcription factor IIIC, polypeptide 1, alpha $220 \mathrm{kd}$ & GTF3Cl & 1.844 down & .0274 & 2975 \\
\hline Pumilio homolog 1 (Drosophila) & PUM1 & 1.843 down & .0257 & 9698 \\
\hline $\begin{array}{l}\text { Splicing factor, arginine/serine-rich } 1 \text { (splicing factor } 2 \text {, } \\
\text { alternate splicing factor) }\end{array}$ & SFRS1 & 1.842 down & .0158 & 6426 \\
\hline Kelch repeat and BTB (POZ) domain containing 2 & $K B T B D 2$ & 1.842 down & .0124 & 25948 \\
\hline $\begin{array}{l}\text { Translocase of inner mitochondrial membrane } \\
44 \text { homolog (yeast) }\end{array}$ & TIMM44 & 1.841 down & .0241 & 10469 \\
\hline 1-Acylglycerol-3-phosphate O-acyltransferase 3 & AGPAT3 & 1.841 down & .011 & 56894 \\
\hline
\end{tabular}


TABLE E2. Continued

\begin{tabular}{llrrr}
\hline \multicolumn{1}{c}{ Gene title } & Symbol & Fold & P value & Gene ID \\
\hline Ezrin & $E Z R$ & 1.840 down & .0279 & 7430 \\
Down syndrome critical region gene 3 & $D S C R 3$ & 1.840 down & .0355 & 10311 \\
v-ets erythroblastosis virus E26 oncogene homolog 1 (avian) & ETS1 & 1.839 down & .0347 & 2113 \\
Ubiquitin-conjugating enzyme E2S///similar & LOC731049 & 1.839 down & .049 & $27338 / / /$ \\
$\quad$ to ubiquitin-conjugating enzyme E2S & ///UBE2S & & 731049
\end{tabular}

(Ubiquitin-conjugating enzyme E2-24 kd)

(Ubiquitin-protein ligase)

(Ubiquitin carrier protein) (E2-EPF5)

Solute carrier family 6 (neurotransmitter transporter, creatine), member 8

Minichromosome maintenance complex component 3 associated protein

Glucocorticoid receptor DNA binding factor 1

Aryl hydrocarbon receptor nuclear translocator

Integrin, alpha 6

La ribonucleoprotein domain family, member 5

Heat shock transcription factor 1

DCP1 decapping enzyme homolog A (S cerevisiae)

Sterile alpha motif domain containing $4 \mathrm{~A}$

Desmin

KIAA 1826

Microtubule associated serine/threonine kinase family member 4

Nuclear factor I/C (CCAAT-binding transcription factor)

Heat shock $70 \mathrm{kd}$ protein 4

Forkhead box $\mathrm{O} 3$

Core-binding factor, beta subunit

Mitogen-activated protein kinase kinase 2

RRN3 RNA polymerase I transcription factor homolog (S cerevisiae)///RRN3 RNA polymerase I transcription factor homolog (S cerevisiae) pseudogene

GCN1 general control of amino-acid synthesis 1-like 1 (yeast)

Cullin 5

CDNA FLJ34585 fis, clone KIDNE2008758

Related RAS viral (r-ras) oncogene homolog 2

MAX dimerization protein 4

SLC6A8

1.837 down

.0172

6535

MCM $3 A P$

1.835 down

.017

8888

GRLF1

1.834 down

.0218

1.832 down $\quad .0179$

$\begin{array}{ll}1.832 \text { down } & .0394 \\ 1.831 \text { down } & .0238\end{array}$

ITGA6

LARP5

HSF 1

$D C P 1 A$

SAMD $4 A$

DES

KIAA1826

MAST4

NFIC

HSPA4

FOXO3

CBFB

$M A P 2 K 2$

1.831 down

.0255

1.829 down $\quad .0142$

1.829 down $\quad .0121$

.0484

1.829 down

1.828 down

.0423

1.828 down $\quad .0448$

1.828 down $\quad .0119$

.0167

1.828 down

1.827 down

.024

1.825 down $\quad .0121$

LOC653390//I

1.822 down

.0295

LOC730092

1.822 down

.0307

I/IRRN3

GCNILI

1.822 down

.0242

1.821 down

.0119

1.821 down

RRAS2

MXD4

1.820 down

.0142

.0206

1.820 down

.0161

Transglutaminase 2 (C polypeptide,

1.820 down

.0419

protein-glutamine-gamma-glutamyltransferase)

Collagen, type IV, alpha 1

Polymerase I and transcript release factor

1.820 down

.0216

1.819 down

.0286

PTRF

$M B D 1$

Methyl-CpG binding domain protein 1

1.819 down

.0245

1.819 down $\quad .0337$

G protein-coupled receptor kinase 5

1.819 down

.0452

GRK5

Protein associated with topoisomerase II homolog 1 (yeast)

PATL1

ILF3

Interleukin enhancer binding factor 3, $90 \mathrm{kd}$

1.818 down

1.818 down

.0147

RHOJ

Chromosome 10 open reading frame 18

C10orf18

1.817 down

.0328

.0278

1.817 down

.0136

NARG2

Transcription factor 25 (basic helix-loop-helix)

1.817 down

TCF 25

SPG7

HNRPM

1.817 down

.0424

.0142

1.817 down $\quad .0368$

Heterogeneous nuclear ribonucleoprotein M

1.815 down

FIGN

Fidgetin

1.814 down

.0206

.0484

1.814 down

.049

1.812 down

.0237

1.812 down

.04

2909

405

3655

23185

3297

55802

23034

1674

84437

375449

4782

3308

2309

865

5605

54700///

653390///

730092

10985

SMURF1

SMAD specific E3 ubiquitin protein
Cold inducible RNA binding protein

CIRBP 
TABLE E2. Continued

\begin{tabular}{|c|c|c|c|c|}
\hline Gene title & Symbol & Fold & $P$ value & Gene ID \\
\hline SLAIN motif family, member 2 & SLAIN2 & 1.812 down & .0309 & 57606 \\
\hline $\begin{array}{l}\text { Required for meiotic nuclear division } 5 \text { homolog } \\
\text { A (S cerevisiae) }\end{array}$ & $R M N D 5 A$ & 1.811 down & .0383 & 64795 \\
\hline SH3 domain protein D19 & SH3D19 & 1.811 down & .0445 & 152503 \\
\hline Pericentriolar material 1 & PCM1 & 1.810 down & .00823 & 5108 \\
\hline Quaking homolog, KH domain RNA binding (mouse) & $Q K I$ & 1.810 down & .0266 & 9444 \\
\hline Insulin-degrading enzyme & $I D E$ & 1.809 down & .0192 & 3416 \\
\hline zinc finger, HIT type 4 & ZNHIT4 & 1.808 down & .018 & 83444 \\
\hline T-box 5 & $T B X 5$ & 1.808 down & .0128 & 6910 \\
\hline $\begin{array}{l}\text { Myeloid/lymphoid or mixed-lineage leukemia } \\
\text { (trithorax homolog, Drosophila); translocated to, } 4\end{array}$ & MLLT4 & 1.807 down & .0283 & 4301 \\
\hline Myosin regulatory light chain interacting protein & MYLIP & 1.807 down & .031 & 29116 \\
\hline Phosphate cytidylyltransferase 1 , choline, alpha & PCYT1A & 1.806 down & .0208 & 5130 \\
\hline RNA binding motif protein $8 \mathrm{~A}$ & $R B M 8 A$ & 1.805 down & .0339 & 9939 \\
\hline Protein kinase $\mathrm{C}$ and casein kinase substrate in neurons 2 & PACSIN2 & 1.804 down & .0284 & 11252 \\
\hline Polymerase (RNA) II (DNA directed) polypeptide E, $25 \mathrm{kd}$ & POLR2E & 1.804 down & .0356 & 5434 \\
\hline Stromal antigen 2 & STAG2 & 1.804 down & .0203 & 10735 \\
\hline Chromosome 1 open reading frame 71 & Clorf71 & 1.803 down & .0187 & 163882 \\
\hline Transmembrane protein 127 & TMEM127 & 1.803 down & .0244 & 55654 \\
\hline Valyl-tRNA synthetase & VARS & 1.802 down & .0291 & 7407 \\
\hline $\begin{array}{l}\text { prosaposin (variant Gaucher disease and variant } \\
\text { metachromatic leukodystrophy) }\end{array}$ & PSAP & 1.801 down & .0324 & 5660 \\
\hline Zinc finger protein 12 & ZNF12 & 1.800 down & .0384 & 7559 \\
\hline
\end{tabular}

